Portland State University

PDXScholar

1993

\title{
Attitudes, Motivations and Expectations of Students and Instructors in an Intensive University ESL Summer Session
}

Ronald Andrew Ragsdale

Portland State University

Follow this and additional works at: https://pdxscholar.library.pdx.edu/open_access_etds

Part of the Applied Linguistics Commons, and the Language and Literacy Education Commons Let us know how access to this document benefits you.

Recommended Citation

Ragsdale, Ronald Andrew, "Attitudes, Motivations and Expectations of Students and Instructors in an Intensive University ESL Summer Session" (1993). Dissertations and Theses. Paper 3567.

https://doi.org/10.15760/etd.5451

This Thesis is brought to you for free and open access. It has been accepted for inclusion in Dissertations and Theses by an authorized administrator of PDXScholar. Please contact us if we can make this document more accessible: pdxscholar@pdx.edu. 
AN ABSTRACT OF THE THESIS OF Ronald Andrew Ragsdale for the Master of Arts in TESOL presented November 3, 1993.

Title: Attitudes, Motivations and Expectations of Students and Instructors in an Intensive University ESL Summer Session

APPROVED BY THE MEMBERS OF THE THESIS COMMITTEE:

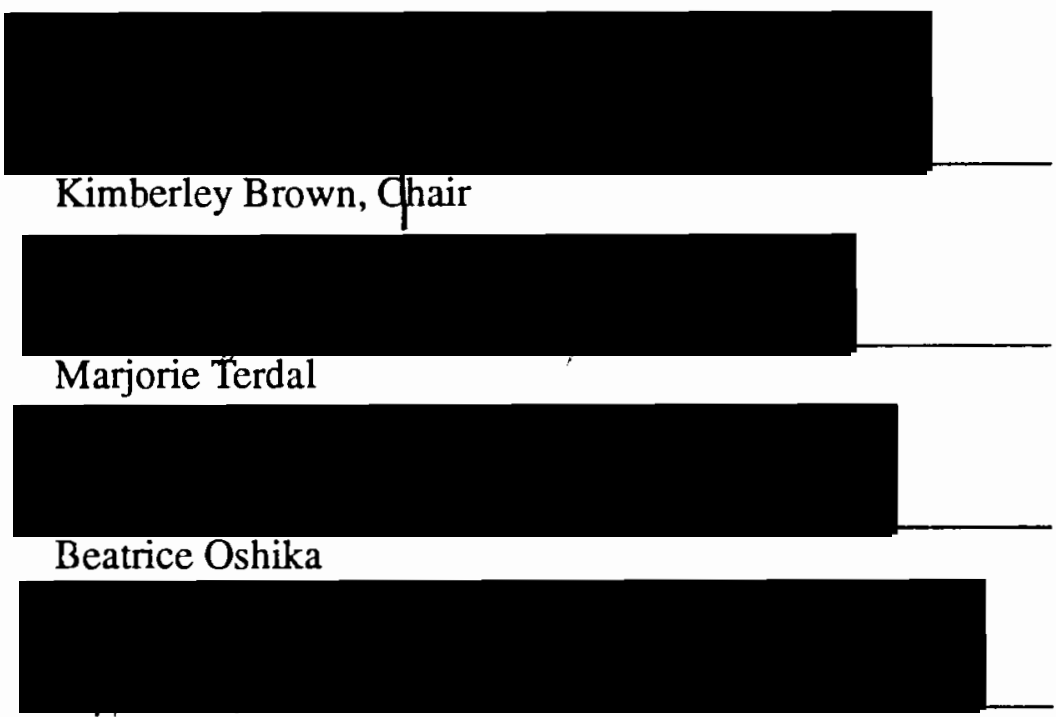

M. Carrol Tama

All international students have specific motivations and expectations when learning English as a Second Language (ESL) in the United States, and recognizing the diversity of those motivations and expectations is the first step toward providing successful second language instruction. This study was designed to elicit the attitudes, expectations and motivations of two unique groups of students studying in the same classes in an ESL summer session at Portland State University (PSU), the preconceptions 
of the instructors, and the impressions and evaluations of the program upon its completion by the students, instructors, coordinators and administrators.

A successful curriculum can only be adapted to fit the needs and expectations of those students who share the same needs and hold the same expectations. When the learners fall into disparate groups, with distinct, and perhaps contrary needs, a given curriculum can be only a compromise at best, and a failure for some at the worst. During the summer session at PSU, the Department of Applied Linguistics offers a full range of intensive ESL courses for visiting international students. In the year of this study there were two distinct groups of students enrolled in the Reading/Writing ESL classes. One group was the traditional eclectic mix of international students who for the most part were on an academic track toward eventual enrollment in regular programs at PSU. The other was a group of Japanese students studying at PSU from Otemae College. These two groups of students entered the program with different motivations for studying English and different expectations from the summer program at PSU.

Because the general academic focus of the program was established in advance of the enrollment of most of these students, it was designed to fit the more traditional students' expectations and motivations. The specific expectations and motivations of the Otemae students were not explicitly considered, leaving the real potential for a negative experience. This is a serious consideration for those designing the curriculum for the summer sessions, for the instructors who are given the task of teaching these distinct groups of students, and for the coordinators of the short term programs who must convince their clients of their effectiveness so they will choose PSU again in the future.

Using a semantic-differential survey to assess the students' attitudes, motivations, and expectations, and comparing the results with general demographic data, it was found that the students did indeed separate into two distinct groups with clear differences in 
motivations and expectations. The Otemae students also formed a large demographic block within the classes which could not be discounted in the lesson plans. Even though the Otemae students had been integrated into the reading and writing classes, these skills were less important to them in the needs analysis portion of the attitude survey than were conversational and pronunciation skills. Reading and writing skills were also rated lower overall by the Otemae students than they were by the traditional students.

These and other factors lend support to the contention that the two groups of students had needs and expectations that were not wholly compatible, which put a strain on the teacher/student relationships as well as on the individual instructors' intended goals. This strain was further verified in instructor interviews, student interviews and in a departmental evaluation at the end of the summer term.

If expectations are not met, or attitudes are not compatible between students and instructors, or motivations are at odds between groups of students, learning can be obstructed, and the experience can be less positive for all concerned. Although the summer session, with Otemae students integrated into the regular classes, went well in the estimation of some, there is convincing evidence that there is need for improvement.

Recommendations for improvement include integrating the Otemae students into speaking and listening classes instead of reading and writing classes, having a curriculum designed with both groups in mind that instructors would have available before the summer term begins, conducting a term by term needs analysis, providing introductory sessions on American classroom style, and attempting to reduce the percentage of Otemae students in any given class by actively recruiting more international ESL students to PSU. 
ATTITUDES, MOTIVATIONS AND EXPECTATIONS

OF STUDENTS AND INSTRUCTORS

IN AN INTENSIVE UNIVERSITY ESL SUMMER SESSION

by

RONALD ANDREW RAGSDALE

A thesis submitted in partial fulfillment of the requirements for the degree of

\section{MASTER OF ARTS}

in

TESOL

Portland State University

1993 


\section{TO THE OFFICE OF GRADUATE STUDIES:}

The members of the Committee approve the thesis of Ronald Andrew Ragsdale presented November 3, 1993.

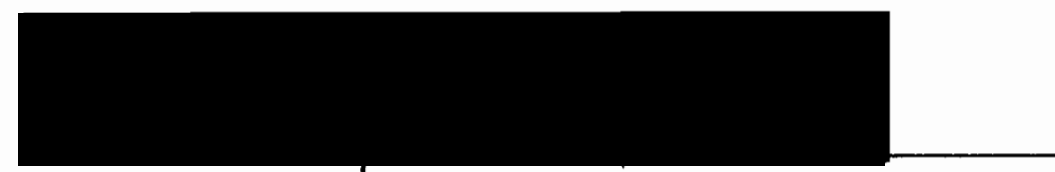

$$
\text { Kimberley Brown, Chair }
$$

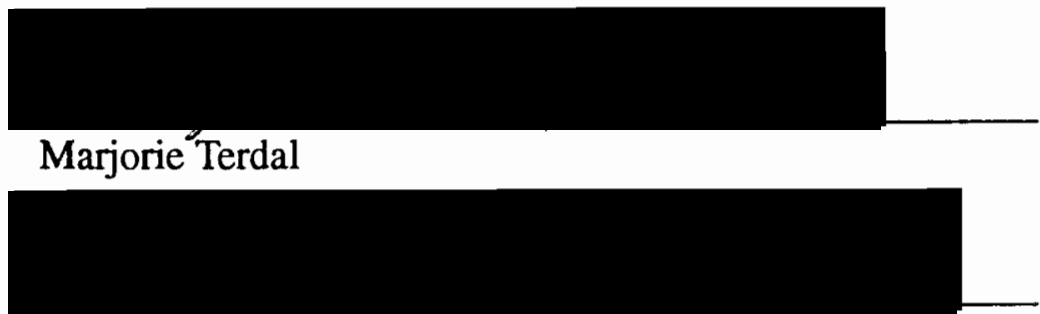

Beatrice Oshika

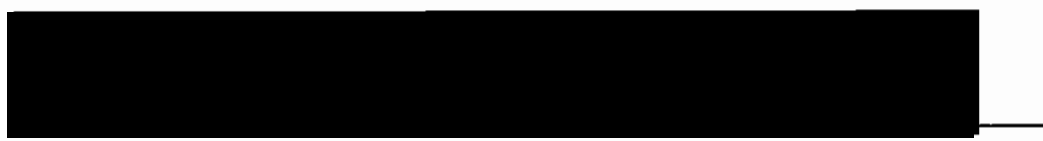

M. Carrol Tama

APPROVED:

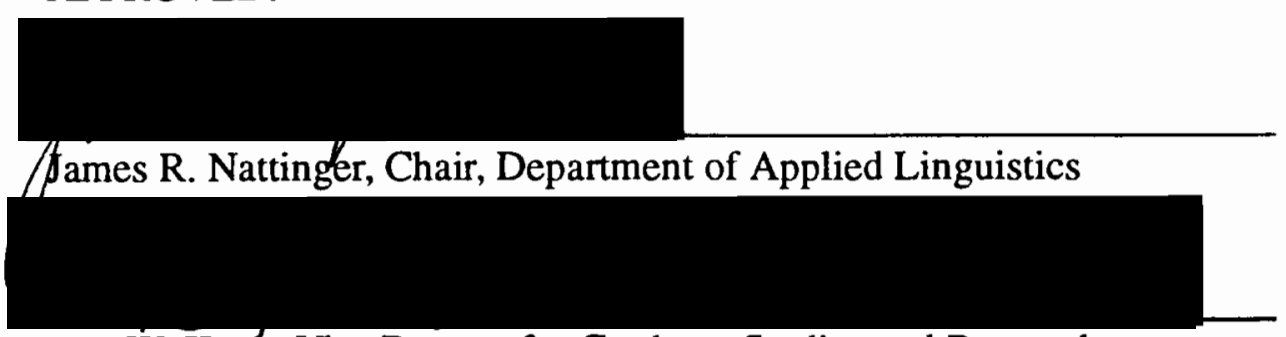

Roy W. Kogh, Vice Provost for Graduate Studies and Research 


\section{ACKNOWLEDGEMENTS}

I have had much good fortune in the timely completion of this thesis project. My first thanks goes to Kim Brown for constantly being supportive of my ideas and for reminding me to focus when my topic would meander or become too broad. Another early acknowledgement that must be made is for a statement that Dr. Kahlil Zonoozy made to me when I first was feeling out ideas for this thesis. He said, "The best thesis is a done thesis." That statement has been my guiding light for the past 9 months.

I also need to express my gratitude to my employer and my coworkers for taking up the slack for me all those days I was gone to class. All my friends also deserve recognition for putting up with my disappearances into the depths of the library for days on end, for my endless monologues about my research topic on those few occasions when I would surface, and for my neglect of their company.

My final and probably deepest gratitude goes to the great designers at Apple who came up with the PowerBook laptop computer, which has made the process of creating a thesis manuscript infinitely easier and actually almosi ciloysiste. 


\section{TABLE OF CONTENTS}

\section{PAGE}

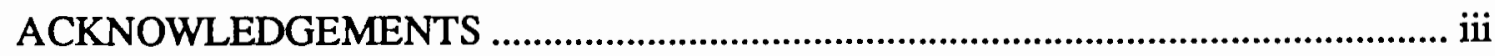

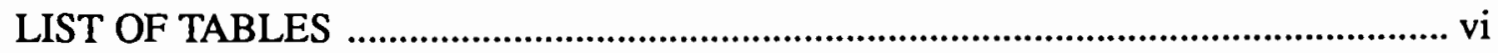

\section{CHAPTER}

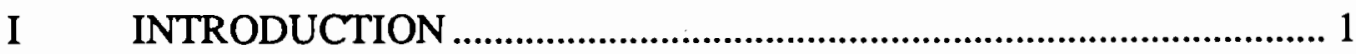

II DESCRIPTION OF THE PROBLEM ….......................................... 4

Research Questions ................................................................... 8

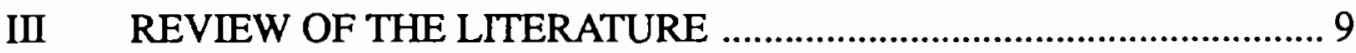

Individual Differences in Second Language Acquisition ............ 9

Affective Variables in Second Language Acquisition

The Specific Role of Attitudes and Motivation 13

The Relationship Between Attitudes, Motivation and Proficiency

The Importance of Measuring Attitudes and Motivation

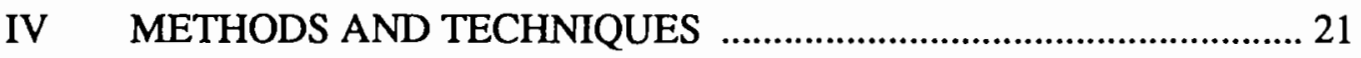

Description and Selection of Subjects ....................................... 22

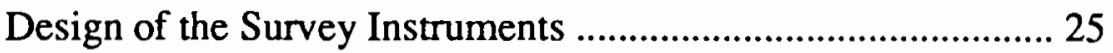

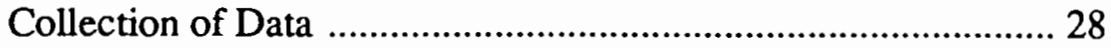

Initial Instructor Survey

Student Survey of Attitudes, Motivations and Expectations Follow-up Student Interviews

Course Evaluations 
Treatment of Data

Summary of Methods and Techniques................................ 32

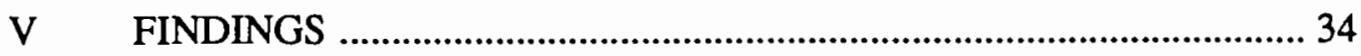

Data from Initial Instructor Questionnaire ........................... 34

Data from Student Questionnaire ..................................... 38

Follow-up Student Interviews ....................................... 44

Data from Otemae Course Evaluations .....................................48

Data from Instructor Survey and Evaluations .......................52

Administrator and Coordinator Interviews .............................55

VI DISCUSSION AND CONCLUSIONS .......................................... 57

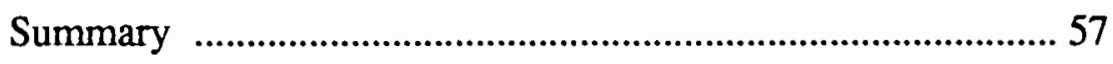

Qualitative Analysis of Findings ..................................... 59

Unanticipated Results ................................................. 67

Implications of the Study .............................................. 69

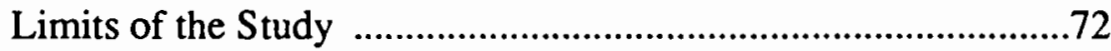

Recommendations for Further Research ............................73

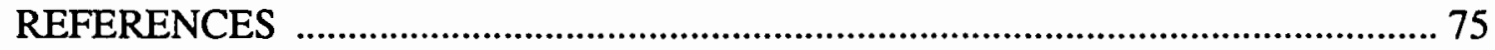

\section{APPENDICES}

A PRELIMINARY INSTRUCTOR SURVEY ................................ 81

B STUDENT SURVEY QUESTIONNAIRE .................................... 84

C FOLLOW-UP STUDENT INTERVIEW FORMAT ....................... 90

D OTEMAE COURSE EVALUATION .......................................... 92

E FOLLOW-UP INSTRUCTOR SURVEY ...................................... 94

F DEPARTMENTAL EVALUATION SURVEY ............................... 96 


\section{LIST OF TABLES}

TABLE

PAGE

I Demographic Breakdown of PSU ESL Student Population

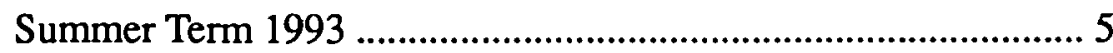

II Otemae and Traditional Students in Reading/Writing Classes

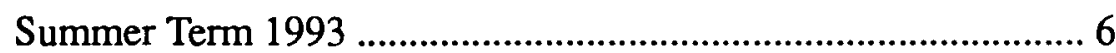

III Demographic Profiles of Population Groups in Level 1-3

Reading/Writing Classes Summer Term 1993............................ 24

IV Student Responses to Survey Questions on Attitudes and

Motivations, Summer Term 1993 ................................................. 40

V Student Self-Assessment of Needs and Expectations

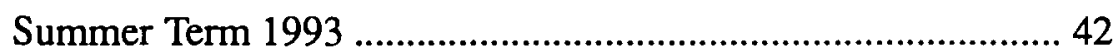

VI Otemae Student Class Evaluations, Part I

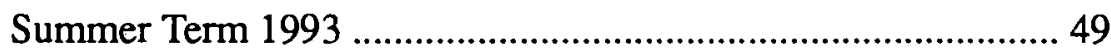




\section{CHAPTER I}

\section{INTRODUCTION}

A major question that faces any second language teacher or researcher is why some students achieve greater proficiency than others, and how that potential for differential success can be addressed in the design of the curriculum and methodology to meet the needs of individual students (Larsen-Freeman \& Long, 1991). To learn a foreign language as an adult to the degree one knows one's native language is probably an impossible task. It is therefore not unrealistic to encounter students who have specific needs and expectations about learning the foreign language. Every student does not need or want to be able to deliver a scientific address to a sophisticated audience, nor, in the case of English learners, does every student want or need to be able to converse casually in idiomatic American English. Recognizing the diversity of needs and expectations is the first step toward providing successful second language instruction.

In assessing individual differences in second language learning, the researcher or instructor must first look at the needs and expectations of the students, the attitudes the students have toward learning the language, and then how these come together to create motivation. As Corder (1973) says, regardless of individual aptitude, specific learning strategies, or pedagogic methodology, it is an unavoidable fact that "given motivation, anyone can learn a language."

However, even if the attitudes and expectations of the students are known, it is often not enough to bring about a successful learning environment for all concerned. If 
the goal of the curriculum is to keep students motivated through a real understanding of their needs, it still remains to define who the students actually are. A successful curriculum can only be adapted to fit the needs and expectations of those students who share the same needs and hold the same expectations. When the learners fall into disparate groups, with distinct, and perhaps contrary needs, a given curriculum can be only a compromise at best, and a failure for some at the worst.

Of course, the optimal situation is to assume that every student has the opportunity, the desire, and the motivation to learn the language so well in all its aspects that individual needs become irrelevant to learning the whole language. This is rarely, if ever, the case. Most students have limited time, limited resources, and specific goals, all of which need to be considered in providing an appropriate language learning environment. Also, many, if not most, English as a Second Language (ESL) programs in the United States are designed to be intensive, short term programs, because of budget and time constraints. This situation is especially true in public institutions, such as Portland State University (PSU).

During the summer session at PSU, the Department of Applied Linguistics offers a full range of intensive ESL courses for visiting international students. Many of these students are continuing their ESL classes from the prior academic year, still on track for eventual enrollment in academic classes at PSU. In the year of this study (1993) there was also an additional group of students who were incorporated into the ESL program for the summer session. This was a group of Japanese students studying at PSU from Otemae College in Japan, on a short term cultural study program. A review of the situation in the ESL program made it apparent that these two groups of students would be entering the program with different motivations for studying English at PSU, and 
unique expectations about what they wanted to learn during the summer program at PSU.

Because the ESL program is primarily established well in advance of the enrollment of most of the students, it would have been impossible for their specific expectations and motivations to be considered in the particular curriculum being offered. Also, given the distinct profile of the two groups of students as outlined in the ensuing chapters, even if the expectations and motivations of either one of the groups was indeed explicitly considered, it is unlikely that the curriculum would be able to meet the expectations and needs of the other group to the same level of satisfaction and effectiveness.

This is a serious consideration for those designing the curriculum for the summer sessions, for the instructors who are given the task of teaching such a diverse group of students, and for the coordinators of the short term programs who must convince clients of their effectiveness so they will choose PSU again in the future.

Measuring students' attitudes, motivations and expectations is one of the first steps that must be undertaken in any evaluation of the effectiveness of a language program, especially a short term program like the summer session at PSU. The next step is to compare the students' expectations with the goals of the program; and to evaluate the effectiveness of the program in light of these variables, in order to make recommendations for improvements. 


\section{CHAPTER II}

\section{DESCRIPTION OF THE PROBLEM}

In any diverse group of international students attending a university in the United States, there will be a wide range of motivations for studying English, and of attitudes exhibited toward American culture and the English language, depending on the cultural values, beliefs and assumptions of each individual. This diversity creates a rich mixture which is easy to look at as a positive situation. The variety of cultural viewpoints provides more contrast for the students, more lively discussions of cultural topics, and a ready justification for instructors to avoid catering to any specific cultural block: the diversity just doesn't allow that luxury. This is the situation that is most often found in the academic ESL program at PSU. Although the majority of ESL students at PSU are from east Asian language backgrounds, primarily Japanese and Chinese, there are students from all over the world, and of widely variant ages, backgrounds, and academic experience (See Table I).

What most have in common is their desire to learn English adequately enough to attain an adequate score on the TOEFL (Test of English as a Foreign Language), or an equivalent proficiency exam, for academic admission to PSU or some other institution, and to allow for some degree of social integration with the University community.

For several years, Otemae College and Otemae Junior College have sent 30-40 women each year to be a part of a summer long American culture and language program conducted by American Heritage Association. In 1992, the program 
TABLE I

DEMOGRAPHIC BREAKDOWN OF PSU ESL STUDENT POPULATION SUMMER TERM 1993 (Figures including Otemae students are in italics)

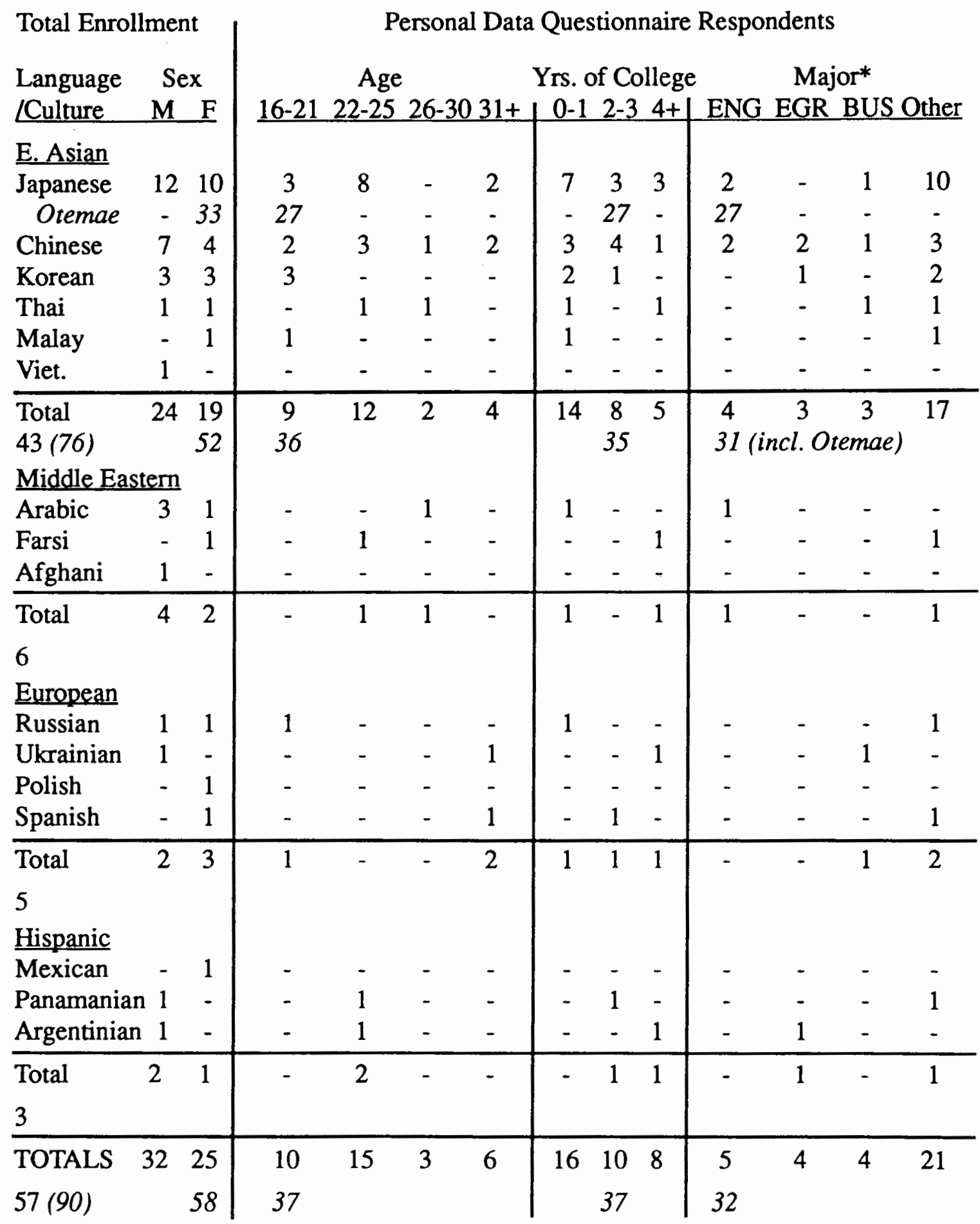

${ }^{*}$ ENG=English/Literature EGR=Engineering BUS=Business/Economics 
was expanded to include academic language instruction at Portland State University. In addition to their afternoon experiential/content classes, which were all-Otemae, they were integrated into the morning ESL reading and writing classes using the same entrance qualifications as the traditional students. This experience was intended to give the students a chance to interact with American university students and to gain language skills through academic coursework.

The students are all women, all from the same college in Japan, all of the same age (20 or 21 years old), all with the same major (English and American Literature), all at the same level of education (junior undergraduates), and all with similar motivations and expectations of their experience in Portland. This homogenous group of students provided much needed enrollment for the ESL program, but also presented a unique problem for the curriculum coordinators and the instructors. The Otemae students, as they will be referred to in this study, presented a cultural bloc too large to ignore or subsume under the cosmopolitan façade of the ESL population, and in some cases became an absolute majority within the classroom (See Table II).

\section{TABLE II}

OTEMAE AND TRADITIONAL STUDENTS IN READING/WRITING CLASSES SUMMER TERM 1993

\begin{tabular}{|c|c|c|c|}
\hline \multicolumn{2}{|c|}{ Level/Section } & Otemae & Traditional \\
\hline \multicolumn{2}{|l|}{ Level 1} & 6 & 3 \\
\hline \multirow[t]{3}{*}{ Level 2} & section $\mathrm{A}$ & 8 & 6 \\
\hline & section $B$ & 7 & 5 \\
\hline & section $\mathrm{C}$ & 4 & 5 \\
\hline \multicolumn{2}{|l|}{ Level 3} & 8 & 13 \\
\hline \multicolumn{2}{|l|}{ Level 4} & - & 14 \\
\hline \multicolumn{2}{|c|}{ TOTALS } & 33 & $46^{*}$ \\
\hline
\end{tabular}

*Not all traditional students were in Reading/Writing classes. 
Looking at Table I again (page 5), it is clear how the demographic makeup of the student ESL population shifted with the incorporation of the Otemae students. Other than the fact that the population was already primarily east Asian, with the largest group being Japanese, the Otemae shifted every other demographic characteristic listed in the table. They shifted the balance heavily in favor of women, lowered the average age, increased the average years of college education and dominated the academic majors.

In consideration of the inevitable influence of such a homogenous group, it is appropriate to look at what that influence has been. In other words, how have the expectations of the program coordinators and instructors been influenced by the presence of the Otemae students, when the program was primarily designed for a diverse group of academic track ESL students. Also, in a two-fold inquiry, how have the Otemae students fared in a program that was not particularly designed to suit their needs and expectations, and how have the traditional students fared in a program potentially overwhelmed by this homogenous group so distinct from their own?

To this point in the inquiry, there has been an assumption that the attitudes, expectations and motivations of the two groups of students are indeed distinct from one another, and cohesive within the separate groups. And so, before any real inquiry can be made into the effectiveness of the program based on these variables, it is necessary to lay out specific questions whose answers will yield insights into the true nature of the situation. The first step, is of course, to determine the students' attitudes, motivations, and expectations, and then to determine if there are any cohesive groups based on these findings, and whether those groups correspond in a significant way with the demographic groups referred to earlier as "traditional students" and "Otemae students."

Only then can the more pertinent questions of effectiveness and appropriateness be adequately answered. To this end, the following questions are outlined: 


\section{RESEARCH QUESTIONS}

1. What are the attitudes and expectations of the PSU summer session ESL instructors...

a) with regard to the students?

b) with regard to the planned curriculum?

2. Do the demographic statistics support the identification of two groups of students?

3. If so, given the population of summer session ESL students at PSU:

What are their attitudes...

a) toward the English language?

b) toward Americans and American culture?

What are their motivations...

a) for studying English?

b) for studying at Portland State University?

What are their expectations...

a) of the program at PSU?

b) for improvement in English?

4. Are there any disparities in attitudes, motivations or expectations...

a) between the demographic groups of students?

b) between the students and the instructors?

5. How do the students perceive the value and success of the program...

a) in terms of language learning?

b) in terms of social integration?

6. How is the appropriateness of the program evaluated by the instructors and the administrators of the program?

7. What recommendations could be made to make the program more appropriate? 


\section{CHAPTER III}

\section{REVIEW OF THE LITERATURE}

Before exploring the questions posed above, it would be useful at this point to look at the theoretical background concerning attitudes and motivation in second language acquisition, and at what part they have played in previous research. This review will explore the hypotheses and arguments that have been made concerning individual differences in second language learning, specifically looking at how attitudes, motivations and expectations are thought to play a role in successful learning, how these factors can be adequately and appropriately measured, and finally, how the implications of the research in these areas impact teaching methodology. Notwithstanding the hypotheses presented by Krashen $(1981 ; 1982)$ differentiating acquisition from learning,

this paper will use the two terms interchangeably, referring only to the general process of internalizing the second or foreign language in all its aspects over the course of time, since the literature is not consistent in the distinction between the two concepts, nor unanimous in agreeing on the validity of making a distinction at all.

\section{INDIVIDUAL DIFFERENCES IN SECOND LANGUAGE LEARNING}

Early explanations of foreign language learning assumed that transfer- both positive and negative-i.e., the interaction between the native language of the learner and the process of acquiring the target language, was the primary factor in determining the rate and efficiency of acquisition. This assumption placed the process of acquisition outside the learner, dependent for success on the particular strengths of the method for 
teaching the language structure (Van Patten, Dvorak, \& Lee, 1987). However, new trends in second language acquisition research, primarily since the early seventies, have focused on the multitude of nonlinguistic variables that are also important in determining the eventual success or failure of second language acquisition. These investigations have established the three essential groups of cognitive, affective, and sociopsychological variables (Genesee \& Hamayan, 1980).

The cognitive variables that have been shown to have some predictive ability include standard measures of language aptitude (Carroll, 1990), and of general intelligence (Boyle, 1987). Neufeld (1979), in outlining the steps needed to arrive at a comprehensive theory of language learning ability, says that Carroll equates language aptitude strictly with the amount of time required by a student to acquire linguistic competence in a second language in formal or classroom settings. In the early fifties, Carroll developed the Modern Language Aptitude Test (MLAT), a measure that is still largely used in the United States and Canada, and whose validity has been supported repeatedly. In reassessing the merits of the MLAT, Carroll (1990) suggests that new research has not identified any major flaws in the design of the battery, which tests the four components of phonetic coding ability, grammatical sensitivity, memory abilities, and inductive language learning ability. If anything, he suggests only "fine-tuning" the current tests in light of new developments in the understanding of cognitive processes, but he remains committed to their validity and appropriateness.

Neufeld counters that all humans are capable of learning language and thus there is no need for or validity in defining any special language-learning aptitude separately measurable from general intelligence. However, Boyle (1987), in a study of 204 Chinese students of English, testing non-linguistic inductive reasoning ability and second language proficiency, provides evidence that intelligence is certainly a predictive factor 
in second language acquisition but that the two are not equivalent. He emphasizes this fact and cautions teachers who use IQ tests for selection or placement.

In light of the conflicting claims of validity of the various measures of aptitude and of what exactly is being measured, it is incumbent on the teacher to determine how to improve leaming by addressing the individual needs of the students using additional considerations.

Other variables that may contribute to individual differences in second language acquisition can include age (Krashen, 1981), perceived social distance (Schumann, 1975), cultural distance (Svanes, 1987), prior language learning experience (Gradman \& Hanania, 1991), degree of encouragement from parents and peers (Gardner \& Lambert, 1972), career choice and sex differences (Ehrman \& Oxford, 1989). But again, even if these factors are significant in determining eventual success and in guiding a theory of language acquisition, they are clearly beyond the influence of the instructor one way or the other, and thus can only be indicators of possible relative success, but not factors to be addressed in the teaching methodology.

Two variables that cross over from the cognitive realm to the affective realm, learning styles and strategies, have been investigated by Oxford (1990) and Ehrman (1990), with encouraging indications that it is possible to train students in the use of more effective strategies. Skehan (1989) points out, however, that since most of the studies dealing with language learning styles are descriptive in nature, it is likely that learners are born with certain learning style preferences that are beyond pedagogical influence. While these variables all show certain signs of influence on second language acquisition, some more significant than others, affective variables seem to be the most fundamental, and may provide fruitful insights into the complex nature of success in second language acquisition (Brown, 1987; Schumann, 1975). 


\section{Affective Variables in Second Language Acquisition}

Affective variables include those aspects of human behavior that are dominated by feelings and personality as opposed to the cognitive, thinking side. This includes feelings both about ourselves and about others (Brown, 1987). Specific affective variables suggested as influencing second language acquisition include self-esteem, inhibition, risk-taking, anxiety, empathy, extroversion, motivation and attitudes (LarsenFreeman \& Long, 1991).

One hypothesis, supported by research of Rubin (1975) and Ehrman and Oxford (1989) is that the more successful, or "good" language learner, is a willing and accurate guesser (see also: Ely, 1989); has a strong, persevering drive to communicate; is often uninhibited and willing to make mistakes (see also: Ely, 1988); focuses on form by looking for patterns; takes advantage of all practice opportunities; monitors his or her own speech (see also: Krashen, 1981); and pays attention to meaning. As much as these traits can be ascertained and measured through the administration of valid instruments, their predictive value is a benefit to teachers assessing the needs and capabilities of their students, and in the design of specific, appropriate teaching practices.

Krashen's (1982) Affective Filter hypothesis incorporates, along with such personality factors as self-confidence, self-image, and level of anxiety, the concepts of motivation and attitudes. In his view, learners enter the classroom with a certain set of attitudes, motivations and abilities, and the role of the teacher is to provide significant comprehensible input for the learner, along with motivational incentives and an environment that lowers anxiety and raises self-confidence, thereby improving attitudes toward the teacher and the language. Given these conditions, successful language acquisition is most likely to occur. 
While it is certainly of theoretical interest to determine whether affective variables influence the relative success of second language acquisition, it is also important to discover how this influence comes about. In a study by Ely (1986) it was posited that affective variables influence a student's voluntary classroom participation which in turn affects second language proficiency. In other words, the level of risk-taking that a student is willing to make is the intermediating factor between the affective variables and the process of acquisition.

\section{THE SPECIFIC ROLE OF ATTITUDES AND MOTIVATION}

Since the landmark publication of Gardner and Lambert's (1972) Attitudes and Motivation in Second Language Learning, considerable research has further supported the hypothesis that achievement and proficiency in a foreign language are related in some degree to measures of attitudes and motivation. Gardner and Lambert identified two orientations toward the learning task that presumably defined the opposite ends of a continuum. At one end they characterized motivation as being integrative, where individuals desired to learn a second language in order to identify with and eventually become a part of the second language culture or community. The other extreme was classified as instrumental motivation, characterized by more pragmatic or utilitarian reasons to learn the second language such as finding better employment or studying at a university where the target language was the language of instruction. They proposed that the integrative motivation was stronger, and since then the research has been exploring this supposedly dichotomous nature of language learning motivation.

While Gardner and Lambert's studies and those of Spolsky (1969) did indeed support the hypothesis that integrative motivation was more closely related to successful 
second language acquisition, other studies have either supported the importance of the instrumental orientation (e.g., Lukmani, 1972), demonstrated a negative correlation between the integrative motivation and successful second language acquisition (Oller, Hudson, \& Liu, 1977), or shown no relationship at all between the two (Chihara \& Oller, 1978). Clément and Kruidenier (1983) postulate two reasons for the disparate findings:

1) ambiguities in the definitions of the concepts of integrative and instrumental orientations and 2) the influence of the linguistic milieu on the individual's orientation (p. 274).

What is lost in all the disagreements about which orientation is more important to successful acquisition, or how to define the spectrum of motivational orientations, is the essential nature of motivation in itself. There is no disagreement that motivation is a critical factor in successful second language acquisition and on that count it should be possible to move forward and ask how attitudes and motivation can be measured, and if necessary, enhanced, in order to provide more effective instruction; because, regardless of aptitude or methodology, the learner's positive or negative attitudes can either enhance or inhibit language acquisition. This is true of the learner's attitude toward the target culture, the teacher, and his or her place in the native culture (Schumann, 1975). Likewise, sustained motivation (i.e., the desire and will to learn the second language), whether integrative or instrumental, seems indispensable to eventual success. Although motivation itself is an important factor in the acquisition of a second language, the type of motivation seems to be of less importance for adult university students, as Svanes (1987) demonstrated in his study of foreign university students studying Norwegian in Bergen, Norway. 
The Relationship Between Attitudes, Motivation and Proficiency

Gradman and Hanania (1991), in a study of 101 international students studying intensive English at the Center for English Language Training at Indiana University, found that the one variable that was particularly significant as a predictor of successful second language acquisition was the extent of active extracurricular individual outside reading. This was true across all ethnic groups, language backgrounds, extent of prior English experience or particular motivational orientation (instrumental vs. integrative). This seems to indicate that motivation is more than simply the need or desire that prompts action (Maslow, 1954) - it must also include the willingness to follow through on the intent (Nida, 1957; Spaulding, 1992).

The relationship between attitudes, motivation and proficiency is one that is characterized by conflicting claims, all backed up by statistical studies and theoretical arguments. The conflict seems to stem, however, from the way the terms have been defined and in what way they are measured (Gardner, 1980). In a study of Thai students of English in an intensive program, Wangsotorn (1987) found a predictive relationship between motivation and what he calls "achievement," but an insignificant relationship between motivation and what he calls "proficiency." These two terms are used in the same sense as Krashen's (1981) "acquisition" and "learning," respectively. However, it is not clear from the study how these two aspects of language learning are differentiated in their measurement, and therefore any statements made regarding the relative predictive ability of motivation toward one or the other is suspect.

The generally positive influence of attitudes and motivation on proficiency, however it is defined, has been further substantiated in a wide variety of studies (e.g., Harshbarger, 1990; Hartill, 1984; Lombardo, 1988; Nelson, Lomax, \& Perlman, 1984; 
Rodriguez-Brown \& Ruesta, 1987). These and other recent studies have attempted to follow on the research and advice of Gardner $(1980 ; 1988)$, who advocates a more comprehensive, indexed measure of attitudes and motivations. This seems to have eliminated many of the arguments against the validity of studies linking attitude/ motivation with proficiency, which either measured too few variables or used imprecise measuring instruments, giving inconsequential results and calling into question the whole idea of the socio-educational model of second language learning (see, e.g., the exchange between Oller, 1982, and Gardner, 1982; and between Au, 1988, and Gardner, 1988).

An interesting variation on the measuring of motivational factors was presented by Genesee, Rogers, and Holobow (1983), who found a positive correlation between the perceived motivational support the learners expect from the target language group (in this case, for Anglophone students learning French in Quebec) and the students' proficiency.

\section{The Importance of Measuring Attitudes and Motivation}

What all this research points out is that attitudinal and motivational variables are indeed separately measurable, significant predictors of eventual success in second language acquisition, to some degree, and in concert with other variables, such as aptitude, age, or cultural distance (Gardner, 1990; Gardner, Lalonde, \& Moorcroft, 1985). The implication to be drawn from this is that finding predictors of eventual success in second language acquisition is an intrinsically valuable goal. And yet, in none of these studies are there clear reasons given for pursuing this goal. This is a different goal, of course, from using measures of second language proficiency as predictors of future academic success (Parry \& Child, 1990), which is a serious consideration for 
administrators, government agencies (Parry \& Stansfield, 1990), and placement personnel (Graham, 1987).

In the end, the only real value of the studies is in statistically validating the assumptions that are held about what constitutes a "good learner" (Rubin, 1975), and what influence attitudes and motivation "actually" have on second language acquisition (Gardner, 1990). Currall and Kirk (1986) suggest that attitudinal and motivational characteristics of participants in intensive courses are particularly important, because "only students with high ability can meet the demands of such courses" (p. 107). But, this still does not address the central question of why it is important to predict whether a student will be able to "meet the demands" of the course. For example, if it is ascertained through the use of some verifiably valid measurement that a given student's attitudes and motivation are not of the right caliber to predict success, is it then incumbent on the placement administrator to deny this student enrollment?

Perhaps a more realistic goal would be to use the measurement of the attitudes and motivations of students simply to assist the teachers in assessing the classroom situation, so that appropriate means may be adopted to improve attitudes, increase motivation, meet the expectations of the students, and thereby increase the chances of success for all the students (Ausubel, 1968). Or, as Day (1987) put it, "the ultimate and far more urgent question is to determine what teachers, curricula, and programs can do to broaden and enhance student motivation in all senses of the word" (p. 264). No matter how many studies support the validity of instruments measuring attitude and motivation by demonstrating their ability to reliably predict language proficiency, there is still a need to address the question of meaningfulness.

In assessing the attitudes, motivations and expectations of foreign students, 
instructors must have available to them instruments designed to elicit information relevant to the classroom situation. A profound central question frequently posed by teachers is what can one do with quantified information once it is available? Often, the evidence is firmest for the most extreme cases or is generalized to the point where it is not relevant to any individual, Accurate information in terms of an individual's motivational strengths and weaknesses is critical for establishing some guidelines for comparison to the ideal. Then, the most important ingredient for the teacher is "how." How can the teacher structure the environment or the material being taught in order to bring about the desired changes in attitudes or motivation (Child, 1984)?

Alpetkin (1981) and England (1982) show that overemphasis on the importance of an integrative motivational orientation in the classroom can often be detrimental to the learning success of students who have a more instrumental motivation, pointing to a need for more individualized assessments. Given the instrumental motives of foreign students to master the target language in order to proceed with their academic studies, there is no reason why educators should not treat these orientations as valid, rather than "indulging in attempts at the inculcation of integrative motives with a view about behavior modification toward assimilation or adaptation" (Alpetkin, p. 277). Aside from being irrelevant to instrumentally oriented students, such efforts could increase the student's affective inhibitions and seriously hurt learning success (England).

Students also often have unrealistic expectations about the amount of language they are capable of learning in a short time. Horwitz (1985) suggests that one way of helping students develop more realistic goals is to ask them to review their past experiences and document the time they have invested in language learning to attain their current level of fluency. 
According to Day (1987), it is essentially incumbent on faculty and administrators to get students to assess the nature and strength of their motivation; to make clear to the students the expectations of the program; and to make the process of pursuing goals relevant to both the students and the program as attractive as possible, while being honest about the necessary effort involved. Day says this is particularly true for short-term intensive language programs where students must maintain a high level of motivation in order to succeed.

It would be very appropriate, then, for teachers to administer a qualitative questionnaire to gather the information relevant to their particular students at that particular time, as was done by Lombardo (1988), Fayer and Krasinski (1984), and England (1982). In addition, Gelder (1992) suggests that assessing attitudes can be augmented with informal interviews with individual subjects. The resulting descriptive statistics can then be used to help shape the focus and content of the course material, and can be used to provide feedback on the success of the program.

There has long been the question of whether motivation and attitudes contribute to or are a result of successful second language acquisition (Skehan, 1989). In fact, Strong (1984) makes a convincing case for integrative attitudes being essentially the result of continuing success at acquiring the target language. It seems most likely that they share a reciprocal relationship, which is a primary incentive for teachers to attempt to influence the motivation and attitudes of their students.

As Brown (1987) argues, attitudes can be changed, often simply by exposure to reality-by encountering people from the culture of the target language. Negative attitudes usually are the result of cultural stereotypes that will not hold up to true experience. Teachers can and should take an active role by introducing students to the 
reality of the host culture, and by dispelling myths about other cultures.

Using Strong's data as a guide, it would seem that as attitudes change to a more favorable light, integrative motivation increases. Beliefs and attitudes are often selffulfilling: as a student gains interest in learning, learning takes place; or, as a belief about another culture changes, so does the perception of that culture. Bacon and Finnemann (1990) believe that the curriculum must be designed to convince students to be willing to deal with the material that they must learn in order to progress. The students must be given every incentive to "be motivated."

Ausubel (1968) gives several practical suggestions for increasing motivation that hold true even in today's second language classroom. First, do not wait for motivation to develop before encouraging a student. Second, always make learning objectives as explicit as possible. Third, make full use of the student's existing interests and motivations. Fourth, maximize cognitive drive by stimulating intellectual curiosity. Fifth, set tasks that are appropriate to each learner's ability. Sixth, help students evaluate their own progress. Seventh, keep track of changes in motivational development. And, lastly, emphasize the student's intrinsic motivations as the key to success.

It is this emphasis on intrinsic motivations that this study contends is the critical element in the effectiveness of a language program. Intrinsic motivation comes from within the student, and is shaped by his or her own attitudes and expectations, but is largely determined by how those attitudes are influenced and whether the expectations are met through the course of the language learning process. The crucial question to be answered here is not how motivation can be influenced, but specifically whether any particular curricular focus can effectively meet the expectations and thereby encourage the intrinsic motivations of disparate groups of students within the same environment. 


\section{CHAPTER IV}

\section{METHODS AND TECHNIQUES}

This study is both qualitative and quantitative in nature, combining the results of an initial questionnaire survey and follow-up surveys and interviews (see Appendices). The quantitative analysis of the questionnaire results provides statistical validation for the definition of the students as distinct groups with differing attitudes and expectations. This data is then used as support for the body of the study, which uses a qualitative focus on the follow up surveys and interviews with students, instructors and administrators.

The questionnaire was administered only to international students enrolled in the summer session intensive ESL program at Portland State University in 1993. All students were given the opportunity to complete the questionnaire, and it was completed voluntarily, with clear consent on the basis of strict confidentiality regarding the personal data, and anonymity regarding specific responses. The response rate was very high, with completed questionnaires returned from 27 of the 33 enrolled Otemae students (82\%) and 34 of the 46 traditional students enrolled in reading and writing classes (74\%).

Based on the responses to the questionnaire, a stratified random sample of eight students were selected for follow-up interviews as suggested by Gelder (1992). Instructors were also surveyed prior to the beginning of classes, to determine their preconceptions about the students they were to teach, and about the planned curriculum and focus of the classes. They were then surveyed again, both specifically for this study and as part of a departmental evaluation, after the final classes had been conducted. 
Finally, administrators and coordinators of the program were interviewed to gain specific insights into the nature of the program and impressions of how successful it was.

The results of the initial questionnaire were not given to the instructors of the various ESL classes, because if they had been and the instructors were then able to use the information to alter or adjust their curriculum to increase its effectiveness, this would not be a study of the program as it was intended to be, but of how it had become.

This quandary is a common issue for "action research" of this type-where the goal of the study is to evaluate and improve a specific teaching situation. Because of the gray area between research and pedagogy, the results of the research are often discounted by theorists and other researchers as invalid or completely ungeneralizable and thus irrelevant to any cohesive theory of second language acquisition. However, the intrinsic value of doing "action research" is in providing examples of how real classroom improvements can be made through a diligent study of specific conditions based on sound theory.

\section{DESCRIPTION AND SELECTION OF SUBJECTS}

Because the Otemae students were only integrated into the reading and writing classes in the mornings, only those classes were considered in the administration of the questionnaire. This eliminated from the study those traditional students taking speaking and listening or grammar classes but not reading and writing. All of those remaining, including all of the Otemae population, were given copies of the Student Survey of Attitudes, Motivations and Expectations (see Appendix B) and were considered to be a part of the study. After receiving the completed questionnaires, it was determined that there were no Otemae students enrolled in level 4 reading and writing classes, so those 
students could also be eliminated from the study, as there was not the issue of conflicting motivations or expectations between the groups within the same classroom. This left a total study population of 33 Otemae students and 32 traditional students, in level 1,2, and 3 reading and writing classes. From the study population, questionnaire responses were received from 27 Otemae students and 24 traditional students.

Based on the demographic data from the returned questionnaires, average profiles emerge of the two population groups that are quite distinct, as the earlier data in Table I suggested. There is a much higher standard deviation in all the categories for the traditional student population than for the Otemae population, indicating a greater diversity of background, experience, and perspective. The traditional students range in age from 16 to 43 , they are evenly split between men and women, they come from eight different language backgrounds, 12 different academic majors, have been studying English from one month to 12 years, and range from high school students to graduate teaching assistants. The defining character of the traditional students is diversity. There is no set of characteristics which can be seen as "typical."

The Otemae students, on the other hand, are extremely atypical in the sense that there is virtually no deviation from the means on any of the demographic criteria. They are a group of students who, on the surface, are statistically identical throughout the population. They are all female, all Japanese, all third-year English literature majors, all basically between 20 and 21 years old, and have been studying English in Japan for the last 8 or 9 years. By their presence in the classrooms, the statistics of the population as a whole are skewed heavily to resemble the Otemae profile (see Table III, p.26). 
TABLE III

DEMOGRAPHIC PROFILES OF POPULATION GROUPS

IN LEVEL 1-3 READING/WRITING CLASSES SUMMER TERM 1993

\begin{tabular}{l|cc|cc|cc} 
& \multicolumn{2}{|c|}{ Traditional $(\mathrm{n}=34)$} & \multicolumn{2}{c|}{ Otemae $(\mathrm{n}=27)$} & \multicolumn{2}{c}{ All Students } \\
\hline Characteristics & Mean & SD & Mean & SD & Mean & SD \\
\hline Age & 23.44 & 5.89 & 20.94 & 0.33 & 22.12 & 4.94 \\
\% Female & $50 \%$ & - & $100 \%$ & - & $75 \%$ & - \\
\% Japanese & $42 \%$ & - & $100 \%$ & - & $73 \%$ & - \\
Years of College & 1.54 & 1.74 & 3.00 & 0.00 & 2.31 & 1.34 \\
\% English Majors & $8 \%$ & - & $100 \%$ & - & $57 \%$ & - \\
Years of English & 5.44 & 3.34 & 8.19 & 0.74 & 6.78 & 2.68 \\
Years in U.S. & 0.91 & 0.84 & 0.25 & 0 & 0.56 & 0.49
\end{tabular}

For the follow-up interviews, a random sample of four subjects from each group was drawn, and these students were invited to participate in the study by meeting to discuss more in depth the feelings and attitudes that were generated by the ESL summer program. Of the eight students selected for interviews, six chose to participate, representing each group equally with three interviews. These six student interviews were not necessarily representative of the groups as a whole, statistically speaking, but were intended to provide more in-depth qualitative data to supplement the general information generated by the questionnaire.

There were five instructors teaching reading and writing in levels 1-3 during the summer session: one level 1 instructor, three level 2 instructors, and one level 3 instructor. Three of them were regular instructors and two were graduate teaching 
assistants working on their MA-TESOL degrees. All of the instructors were given the opportunity to respond to the initial survey of expectations for the summer classes (Appendix A), and four of them did in fact respond. The response to the follow-up survey (Appendix E) and the departmental evaluation at the end of the term (Appendix F) came from three of these four.

In addition to the comments provided by the instructors on the surveys and evaluation forms, the program administrator and the curriculum coordinator were interviewed at the beginning and at the end of the term to gather more detailed information and opinions.

\section{DESIGN OF THE SURVEY INSTRUMENTS}

The student survey of attitudes, motivations and expectations (Appendix B) was designed to elicit basic demographic data and to gauge each student's personal perspective on learning English. The first section of questions, regarding the confidential personal information consisted of questions that relate directly or indirectly to factors which could relate to relative language learning success, such as age, first language, previous language learning experience, years of college education, length of time in the U.S., etc. Questions regarding sex, university major, and nationality were included to see if there was any relationship at all between these factors and attitudes or motivations.

These questions and the survey questions were initially planned to be translated into the native languages of the students to eliminate the possibility of misunderstanding on the part of the students. However, it was decided that there was an equal potential for misunderstanding or mistranslation on the part of the researcher, and very likely a lack of comparable meaning from one first language to another. With these considerations in 
mind, the survey was written in English for all students in all levels in such a manner that to eliminate confusing terminology or complex grammatical structures. The final wording was decided on after several pilot tests with non-native speakers whose level of English proficiency was very high, and with non-native speakers with comparable proficiency to the intended subjects. They were able to provide suggestions that anticipated difficult vocabulary or concepts, allowing for changes to be made before the problems occurred.

In the second section, the attitudes and motivations section of the survey, the questions were constructed using a five-point semantic differential scale to give the students a simple way of allowing flexibility in answering, but without testing their ability to respond to an open ended question. This type of scale also provides a clean and consistent way of analyzing and comparing data from students with diverse backgrounds and skill levels. The order of the semantic differentials (i.e. whether the "positive" end of the scale were on the left or on the right) was alternated randomly to help prevent students from simply checking one extreme or the other on all questions after detecting a possible pattern. This random ordering of the scales was intended to encourage the students to read each question carefully and then provide the most appropriate answer to fit their opinions or perceptions.

The particular questions being asked were adapted from various assessment instruments used in previous research (England, 1982; Lombardo, 1988; and others) and were designed to elicit attitudes toward American culture and the English language, motivations for studying English and for coming to the United States, and expectations about future use of English in work, school, and everyday life.

The third section deals with a self-assessment of skills and needs, which could be 
tallied and then compared to the planned curriculum and to the course evaluations at the end of the term to see if expectations were being met. The various skills listed in the survey were selected to represent a wide range of language uses, ranging from very academic (history of the language) to very communicative (conversation) or cultural (understanding Americans). Each skill was then rated on a self-ascessinent scale trom "not good" to "very good" and each skill was rated according to how much more the student wanted to learn while studying at Portland State University, from "not much" to "very much." In the final analysis of the results from this section of the survey, a skill would be considered critical to a successful curriculum if it was consistently rated high in the "want to learn" column and consistently rated low in the self-assessment of skill level column. Conversely, a skill which was rated low in the "want to learn more" column and high in the self-assessment column should be of less importance in the curriculum plan. If the latter type of skills were focused on in the classroom, students could become bored, unmotivated or apathetic about learning the language.

A program and course evaluation was also given to the Otemre students at the end of the summer term. This evaluation survey was created and administered by the Otemae program director, who made the data available for this study. The regular ESL students were not all given standard course evaluation forms to complete, as it is not a requirement of the department. Only one instructor collected evaluations and that data has been used to augment the Otemae student evaluations. It would have been helpful to have course evaluations from all the students, not only for this study, but for future reference by the program coordinators and the instructors themselves.

Instructor surveys and interviews were designed simply to elicit as much pertinent information as possible concerning the ESL classes, the integration program in 
general, and suggestions for change and improvement. They were purposely left openended to encourage personal responses and more information than a set of directed questions might generate.

The different instruments and means used to gather data included the following:

1. Initial instructor survey of expectations and curriculum plans (Appendix A).

2. Student survey of attitudes, motivations and expectations (Appendix B).

3. Follow-up student interviews (Appendix C).

4. Student course and program evaluations (Appendix D).

5. Instructor course evaluations and program surveys (Appendix E).

6. Departmental program evaluations (Appendix F).

7. Administrator and curriculum coordinator interviews.

\section{COLLECTION OF DATA}

\section{Initial Instructor Survey}

The initial instructor survey was distributed at the last faculty meeting prior to the beginning of summer term, with instructions that the survey be completed and retumed before classes actually started. The intention was to get the instructors' preconceptions about their probable students, the planned lessons, and their expectations for the course goals. The one reading/writing instructor who did not return a survey was not present at the faculty meeting, and was made aware of the research project on the first day of class. The ESL coordinator and all of the instructors were very willing to participate in the study and were eager to cooperate in any way. 


\section{Student Survey of Attitudes, Motivations and Expectations}

Also, prior to the beginning of actual classes, permission was received from the instructors to take ten minutes of class time sometime during the first week to distribute and introduce the student survey questionnaire. It was decided after some consultation with the instructors that the second week of class would be better, because during the first week some students might yet be shifted to other levels based on the initial evaluation of their skills and proficiency in the classroom. Once everyone had settled in to their appropriate level, the questionnaire was introduced to the students.

The classes were interrupted at the beginning of the period, immediately after roll had been taken, so that the lesson plan would not be disrupted. I entered the classroom and was introduced by the instructor as a graduate student conducting a survey of the students' language learning experiences, attitudes and motivations. I then explained to the class as a whole that individual participation in the survey was completely voluntary and would not affect their grades. In order to keep their responses absolutely anonymous, all the students were given a questionnaire to read over and take home. They were instructed to decide if they wanted to fill it out on their own and return it the next day to place in an envelope, either completed or not. In this way, no one in the class would know who had filled it out and who had not. The method worked well and there were few blanks returned from any of the classes. All the students seemed happy to participate and the minimal classroom interruption was easy for the teachers to handle.

\section{Follow-up Student Interviews}

Based on the demographic data taken from the returned questionnaires, the students were split into the two groups of traditional and Otemae students, and then stratified by language groups for the traditional students (Japanese, other Asian, and Other). From these 
groups eight individuals were selected at random for personal interviews (four Otemae and four traditional). The prospective interviewees were notified in writing of my desire to interview them for the study and they were given the option of accepting or declining the request. Of these eight students, three of the Otemae students responded and three of the traditional students responded (one male Japanese, one female Chinese, and one male Russian). The interviews were scheduled in the latter half of the term, to gauge the attitudes and impressions of the students as the classes progressed.

The interviews were all held in a neutral location, either in the cafeteria or outside in the park on campus, at a time convenient for the interviewees. After explaining that their participation was absolutely voluntary and confidential, and receiving their permission to continue, we talked about their feelings about the reading/writing classes, about their progress through the term, their feelings toward the other students and the instructors, and their overall evaluation of the program.

The format of the interviews was informal, using a series of guiding questions (Appendix C) that would prompt the students to talk freely of their opinions and impressions. The interviews were not taped, to reduce any possible intimidation that might be felt by the students. I recorded field notes in a small tablet, writing as we talked, using an abbreviated short hand to record particularly pertinent dialogue. The time taken in these interviews was generally from three quarters of an hour to an hour, and the students always seemed at ease and happy to talk about their experiences in English, though their levels of conversational proficiency varied greatly. Although the placement levels of the Otemae and the traditional students were comparable for the reading and writing classes, the conversational skills of the traditional students were considerably greater on the whole. 


\section{Course Evaluations}

Several means were used to collect course evaluation data. The follow-up instructor surveys were distributed to the reading and writing instructors at the end of the term, after final exams were administered and grades had been assigned. Likewise, the departmental program evaluations were distributed by the Otemae curriculum coordinator to get feedback on the effectiveness of the integration of students in the reading and writing classes. The student evaluations were completed by the students and turned in on or near the last day of classes, and were completed at the discretion of the individual instructors.

During the summer months, both while classes were in session and following the end of the term, the program administrators and the curriculum coordinator were interviewed informally to gain further insights into the effectiveness of the integration program.

\section{TREATMENT OF DATA}

All the information gathered by any means for this study has been kept strictly anonymous and the personal data from the students has only been used to define the demographic characteristics of the groups, not to single out specific individuals as illustrations. The interviews in particular have been kept anonymous and are intended only to provide more detailed and personal comments which can be seen as representative examples of student attitudes and impressions. The instructors' and administrators' identities have been kept anonymous as well, to protect individuals from unwanted attention that might derive from the publication of this study. All the data are available for future study or for assisting in administrative and instructional decisions. 


\section{SUMMARY OF METHODS AND TECHNIQUES}

The ultimate purpose of this study is to provide information about the attitudes, motivations and expectations of the students and to make recommendations to the administrators and instructors in the summer session ESL program at PSU, concerning the integration of the Otemae and traditional students into the same classes. These recommendations are made based on the qualitative nature of the information that has been gathered and analyzed, and it was therefore necessary to use the most appropriate means to gather this highly subjective, qualitative material with the least amount of intrusion and disruption of the teaching and learning processes.

The questionnaire survey of attitudes, motivations and expectations made the procedure simple and direct for the students. The interviews and instructor surveys were kept to a necessary minimum and were conducted in an informal style which dropped barriers to easy communication. In all instances, I feel the participants in the study acted openly and willingly, giving honest input, and were at ease with the data collection procedures.

The student surveys provided a means to quantify some of the data and to create statistical relationships between the responses and the demographic data, and to provide quantitative contrasts between the two groups of students which enabled them to be defined as such. This statistical contrast between the Otemae students and the traditional students, both demographically and in terms of their expectations and motivations, provides the basis for the rest of the study. The conclusions that are drawn, however, are qualitative in nature, are not intended to be quantifiable, and are not significant for any statistical objective relationships, but rather for their overt subjective nature. The statistical data defines what is happening in the students' minds regarding their English 
language learning experiences at PSU. The qualitative data provides many clues about why. Together, the data generated by this study suggest possible recommendations for making the integration process truly integrative and effective for all students. 


\section{CHAPTER V}

\section{FINDINGS}

The results of this study are presented here in the same chronological order that the data was collected, starting at the beginning of the term with the initial instructor surveys and progressing through to the end of the term with the course evaluations and interviews. In this way the material can be evaluated in its appropriate context, without the direct influence of later findings. The material as a whole will be discussed in chapter six, which ties together all the different elements and presents conclusions and recommendations that can be drawn from the analysis.

\section{DATA FROM INITIAL INSTRUCTOR QUESTIONNAIRE}

The first step in the process was the distribution of survey questionnaires to the instructors of the reading and writing classes in levels one, two and three. All of the ESL instructors for the summer session were given these surveys, before it was determined that the Otemae students had placed only in levels one, two and three, and would only be integrated into the reading and writing classes. Since the intent of this study is to analyze the effects of integrating the two groups of students, the results discussed here will reflect only the responses from the appropriate teachers.

Five instructors were involved in teaching the integrated classes, one for level one, three for level two and one for level three. Of these, all responded to the initial survey except one of the level two instructors, who was not present at the faculty meeting 
when the survey was presented. Having response from instructors in all three levels should provide a good indication of the faculty's expectations for the program and from their prospective students.

The questions asked of the instructors are given here with a sampling of responses from the teachers concerned (see Appendix A for the complete questionnaire).

How many students do you expect to be in the class?

"Probably 10 to 15 in level one."

"Hard to know as yet...it could be 20 to 25 in level two, or we might split the class into two or three sections if we get more than 30 students."

What language backgrounds do you expect the students to come from?

On average, the instructors said Japanese (Otemae, and others) would probably make up to $50 \%$ and Korean $30 \%$. [Note: this was when it was thought there would be a large group of students coming from Ulsan, Korea. They were unable to obtain proper visas in time, however, and did not attend.] Others might be mostly Asian and middleeastern.

Do you think your students will all be at a similar level of proficiency?

One level two instructor answered: "Yes, if our placement procedures, using the CELT, Michigan and writing pre-tests reflect true proficiency." All the others responded simply: "No."

Do you think all your students will have similar expectations from the class?

Three of the four instructors answered simply: "No." The other reflected more openly and more pertinent to the subject of this study, saying that the admitted 
(traditional) students may expect a more academic focus, while the Otemae (and Olsan) students may want a more functional and content-based focus.

What do you think their expectations and motivations might be?

"Fun stuff - learn about Portland, Oregon, and the United States."

"Learn about cultural patterns, holidays, etc. A few might want to start learning how to write a college essay."

"To improve general reading and writing skills."

Do you plan to do any needs assessment at the beginning of the term? Such as?

"Informal classroom discussion to assess past experience and plans for the future."

"Maybe a little in terms of topics/skills they would like to focus on." "Sample writing."

Do you plan to provide individualized instruction based on needs? Or other criteria, such as first language?

One instructor hoped to have reading and writing conferences with individual students to address their specific needs. Another would consider first language concerns in the lesson plans.

Is your curriculum for the class pretty much decided beforehand? If so, by whom? And, if so, is it based on a specific text?

All of the instructors indicated they had control of their curriculum and had made some decisions on texts and activities, but would remain flexible as the course progressed. 
What broad topics, skills, strategies, or functions do you hope to cover?

All four instructors emphasized working with "bottom-up" [sic] reading skills such as skimming and scanning, and finding main ideas and supporting ideas. One instructor planned to include pleasure reading in her course plan. For writing skills, besides using traditional academic teaching methods such as working from sentences to short paragraphs, the instructors suggested possible lesson plans focusing on punctuation, vocabulary building, dictionary usage, typing and word-processing skills, identifying prefixes and suffixes, and an ambitious newspaper production project.

Do you feel this program is primarily focused on academic language skills?

Two of the teachers answered yes. The other two expressed reservations about the summer term being too academic. One instructor suggested that most students would not have academic goals. The other said that during the summer term the program "seems to shift to a less academic focus."

How will you know if your instruction has been successful? How will the students know? Completed projects, quizzes, self-evaluation at the end of the term.

Briefly, the information collected from the instructors via this survey indicate a realization that the students would have different expectations and motivations, but how that understanding was to be taken into consideration differed from one instructor to another. Two of the instructors were definitely leaning toward a traditional, academic program focusing on specific language skills, even though they realized that some students may not have academic goals. One instructor was more flexible, but still was not sure how the class should be focused. The other was definitely in favor of a less 
academic focus, with more functional and cultural elements.

The lack of consensus on the part of the instructors on many of the issues, such as academic focus, needs assessment and curriculum design, reveals a lack of coherent program goals about how the integrated classes should best be conducted.

\section{DATA FROM STUDENT QUESTIONNAIRE}

The centerpiece of this study was the student questionnaire survey of attitudes, motivations and expectations. The initial part of the survey consisting of personal and demographic information was presented statistically earlier in the study (Table I and Table III). Data from this section that have not been reported so far include:

7. Does your father speak English?

8. Does your mother speak English?

9. What other languages do you speak?

These were intended to gauge whether the student had active parental influence in learning English (Gardner \& Lambert, 1972), and whether previous language learning experience might help in learning English. It is well supported that previous second language learning experience does help when learning additional languages (Gradman \& Hanania, 1991). Based on the returned questionnaires, $38 \%$ of the traditional students had fathers who spoke English versus $26 \%$ of the Otemae students. As to their mothers speaking English, 21\% of the traditional students said yes, to $19 \%$ of the Otemae students.

On the question of prior second language learning experience, only four students spoke another language besides their native language and English, and these were all traditional students. Three of those four learned the third language because it was an 
additional language in their home or country. Only one student had learned a third language academically.

The rest of the questionnaire asked about the students' attitudes, motivations and expectations, and the data from those responses are presented statistically in Table IV and Table V.

The second section of the student survey dealt with both attitudes and motivations, keying in on specific elements which have been addressed in the literature as relevant to language learning success. As stated earlier, the questions were presented as a semantic differential scale, ranging from one extreme to the other in possible response, giving the students flexibility in responding without testing their language proficiency at the same time.

Quantitative measures of qualitative data like this can be subject to many threats to internal validity, particularly the desire on the part of the subjects to try to guess the "correct" answer in order to "help" the researcher (Brown, 1988). It is best to keep in mind that questionnaire respondents are under no obligation to answer honestly, and therefore the data derived from this type of instrument can only be assumed to reflect the actual conditions of the respondents.

The first six questions dealt directly or indirectly with attitudes toward the English language, Americans and American culture. The next eight questions dealt directly or indirectly with motivations for studying in the U.S., for learning English at all, and for using English in their home countries. Without saying which motivating factors are more or less important to long term success in second language acquisition, based on the review of previous research, motivation in and of itself is the relevant factor. Each of the questions is stated below, in Table IV, with the direction of the semantic scale 
TABLE IV

STUDENT RESPONSES TO SURVEY QUESTIONS ON ATTITUDES AND MOTIVATIONS, SUMMER TERM 1993

\begin{tabular}{l|c|c|c}
\hline \multicolumn{1}{c|}{ Survey Questions } & $\begin{array}{c}\text { Trad. } \\
(\mathrm{n}=34) \\
\text { Avg. }\end{array}$ & $\begin{array}{c}\text { Otemae } \\
(\mathrm{n}=27)\end{array}$ \\
Avg. SD
\end{tabular}


indicated, followed by the average response of each group. A low score (1) reflects a more positive attitude or more highly motivated individual. For the purposes of this study, it is deemed that studying by personal choice rather than for a college requirement reflects a higher motivation. All the other statements are unambiguous in their import.

For those questions concerned with attitudes, the differences between the two groups are negligible, with both groups showing a very positive attitude toward learning English in the American cultural setting, with the Otemae students displaying a consistently tighter range of responses, reflecting a more cohesive cultural perspective. The only noticeable difference is in the assessment of the difficulty of learning English. The Otemae students were more likely to judge the difficulty to be very high, again with a smaller standard deviation reflecting a more consistent opinion within the group.

Looking at the average response for the questions regarding motivation, it is obvious that both groups are very highly motivated to learn English, and even display the same relative influences from the various motivating factors being assessed. Three of the highest ranked factors for both groups are parental influence, job skills, and the importance of international communication with other speakers of English. The only noticeable differences in motivational influences between the two groups are the relatively greater lack of opportunity to speak English in their native country and with their friends on the part of the Otemae students.

The question asking whether English is a requirement for college, or a personal choice turned out to be a very ambiguous question, and probably should have been reworded to be more definitive about influence on motivation. Many students, especially the Otemae students, have chosen a college course of study (English literature) which requires the study of English. A more appropriate question might have been if the 
educational system in general in their home country requires the study of English.

The third portion of the survey listed 17 specific skills or activities involving the use of and study of English, asking the students to assess their own skill level and rate their desire to learn more, for each skill in the list. On the self-assessment scale, a low

\section{TABLE V}

\section{STUDENT SELF-ASSESSMENT OF NEEDS AND EXPECTATIONS SUMMER TERM 1993}

Traditional Students $(n=34) \quad$ Otemae Students $(n=27)$

\begin{tabular}{|c|c|c|c|c|c|c|}
\hline SKILLS & $\begin{array}{c}\text { Need } \\
\text { Avg. } S D\end{array}$ & $\begin{array}{l}\text { Expect } \\
\text { Avg. } S D\end{array}$ & Rank & $\begin{array}{c}\text { Need } \\
\text { Avg. } S D\end{array}$ & $\begin{array}{l}\text { Expect } \\
\text { Avg. } S D\end{array}$ & Rank \\
\hline taking notes & 1.961 .37 & 2.670 .92 & 16 & $2.00 \quad 1.14$ & $2.63 \quad 1.08$ & 13 \\
\hline reading literature and poetry & 1.750 .99 & 2.001 .10 & 12 & $2.67 \quad 1.39$ & 2.260 .94 & 16 \\
\hline pronunciation & 1.170 .48 & 2.751 .19 & 2 & 1.040 .19 & 1.891 .05 & 2 \\
\hline grammar & 1.500 .93 & 2.580 .88 & 8 & 1.370 .84 & 1.931 .04 & 7 \\
\hline reading textbooks & 1.540 .83 & 2.920 .97 & 9 & $2.22 \quad 1.22$ & $2.48 \quad 0.75$ & 14 \\
\hline conversation & 1.170 .38 & $2.58 \quad 1.28$ & 1 & 1.000 .00 & 1.931 .11 & 1 \\
\hline history of the language & $2.42 \quad 1.28$ & 1.961 .12 & 17 & 3.041 .32 & $1.48 \quad 0.89$ & 17 \\
\hline writing for class & 1.420 .58 & $2.67 \quad 1.09$ & 4 & 1.670 .88 & $2.07 \quad 0.92$ & 9 \\
\hline business writing & 1.711 .00 & $2.17 \quad 1.17$ & 14 & 2.331 .36 & 1.190 .48 & 15 \\
\hline American culture & 1.881 .03 & 2.830 .87 & 15 & 1.850 .95 & 2.040 .81 & 11 \\
\hline understanding Americans & 1.580 .78 & $2.88 \quad 1.08$ & 10 & 1.410 .75 & 2.220 .97 & 6 \\
\hline reading newspapers & 1.500 .83 & 2.420 .97 & 6 & $1.93 \quad 1.17$ & $\begin{array}{lll}1.70 & 0.91\end{array}$ & 12 \\
\hline vocabulary & 1.330 .64 & 2.211 .14 & 3 & 1.220 .58 & 1.741 .10 & 5 \\
\hline speaking to the class & 1.170 .64 & 2.631 .24 & 5 & 1.150 .46 & 2.001 .14 & 4 \\
\hline listening to mass media & 1.460 .83 & $3.08 \quad 1.25$ & 13 & 1.070 .27 & 2.371 .11 & 3 \\
\hline spelling & 1.500 .83 & 2.541 .02 & 7 & 1.520 .80 & 2.561 .15 & 10 \\
\hline typing (word processing) & $1.71 \quad 1.04$ & $1.88 \quad 1.08$ & 11 & 1.440 .97 & $1.48 \quad 0.85$ & 8 \\
\hline
\end{tabular}


score would reflect a low skill level, indicating a strong need for that student. On the expectations scale, a low score would reflect a strong desire to learn more for that particular skill, indicating a strong expectation on the part of the student to receive instruction in those areas. In Table V, the skills are listed, with the corresponding average scores and standard deviations for the two groups of students. The ranking of the skills is based on a formula which weights the students' expectations (or wants) over their selfassessed needs, while also giving weight to a tighter standard deviation, reflecting a stronger consensus from the group. The weighting of wants over self-assessed needs provides for a higher ranking of those areas where students show a marked preference for learning over those areas where they show relatively little interest, even if their selfassessed skills are quite low (as with the case of the study of the history of English). The formula used was as follows:

(Avg. Need Score x Avg. Need SD) + (Avg. Expect. Score x Avg. Expect. SD x 3)

This formula produced factors which were then ranked in descending order, reflecting a lower initial score and a lower standard deviation as being a more critical skill to be addressed in the classroom, based on the results of this survey.

The top five skills for each group are nearly identical, with conversation and pronunciation easily the most desired skills to be addressed, with vocabulary and speaking holding two of the other three spots. The only differences in the top five are: 1) the importance that academic writing holds for the traditional students, who placed it as number four, where the Otemae students have it ranked number nine; and 2) the Otemae students have ranked listening to mass media (radio, movies, TV) as number three, where the traditional students show less interest by placing it near the bottom at number 13 . 
One other interesting piece of data to be drawn from this analysis is the fact that the traditional students rated all reading skills (reading literature and poetry - 12, reading textbooks -9 , and reading newspapers - 6) higher than did the Otemae students $(16,14$, and 12 , respectively). These skills were also very low on the list for the Otemae students. Writing skills were also very low on the Otemae students' ranking. (taking notes - 16, writing for class -9 , business writing -15 ). In fact, of the bottom five rankings for the Otemae students, all are academic language skills, whereas for the traditional students, the bottom five also include listening to mass media and American culture.

These disparities aside, it should be noted that other than studying the history of the language, all the skills were rated as desirable or very desirable by all the students. The rankings reflect mostly subtle but telling differences between the two groups.

It is also interesting to note that aside from reading literature and poetry (which is understandable), the Otemae students consistently rated their own skill levels lower than did the traditional students. And likewise, with the exception of the various academic skills at the bottom of their list, the Otemae students have consistently ranked their desire to learn the other skills higher than did the traditional students.

\section{FOLLOW-UP STUDENT INTERVIEWS}

The interviews with the students took place during the final week of the term, so there was time for them to have formed opinions and impressions of their experiences during the summer. Although the six students who assented were interviewed independently, their general responses are grouped together here following each of the guiding questions that were asked during the interview. The actual interviews covered much more than these ten questions in order to establish rapport and to make the 
conversations flow more easily for the students. What is presented here gives only that information that is pertinent to the study and is presented as a unit for each of the two study groups to preserve the anonymity of the individuals.

How did you like your ESL classes this summer?

A common remark from many of the students, including all the Otemae students who were interviewed is summarized by these comments from one Otemae Japanese student in level two: "Homework is hard and classes are long. Nine to three every day. Is short time to learn much." However, one of the traditional students remarked that the classes were too easy, with much of the class time devoted to games and exercises not really related to the homework. The other students interviewed enjoyed the classes, however, and thought that it was a good experience.

What classes did you enjoy the most? The least?

The traditional students all expressed a preference for the listening and speaking classes, saying that the reading and writing classes had too much homework. One nonOtemae Japanese student also remarked that the level two grammar class was too easy and was just a review of what was taught in Japan. "Sometime it is a waste of time, but Japanese will not say so to the teacher because they like her." Of course, these remarks are referring to classes not being considered by this study because the two groups of students were only integrated in the reading and writing classes. However, it is interesting that none of the students expressed a preference for the reading and writing classes. With the traditional students it was unanimously the speaking and listening classes that were favored, while for the Otemae students, their preferences lay with the non-credit courses like Drama and Children's Literature, rather than with the reading and writing ESL classes. 
Did you learn as much as you hoped to at the start of the summer?

One non-Otemae student said that "writing techniques were not taught" but it was not clear what was meant. All of the students expressed some dismay that their conversation skills had not improved much over the summer. An Otemae student said that "We have to speak somebody. If I don't talk somebody my English is very bad." Only one student thought that the time spent in the ESL program was a waste, and primarily because of this lack of improved communication skills.

Were there any specific problems that you had in class?

The most common problem that the students had was not being understood by the teacher. This was mentioned by two of the three Otemae students and one of the traditional students. Another problem mentioned was the inability of some instructors to answer grammar questions clearly and with certainty. The students want to know the right way to say something and want to be told when they do it wrong.

Do you feel your needs as a student were understood?

This question brought a consistent response from the Otemae students, who all wished they had been able to take the speaking and listening ESL classes rather than the reading and writing. They all felt that reading and writing could just as easily be studied in Japan. They came to the U.S. to meet with and learn to talk to Americans. Two of the three traditional students thought the classes were not helping them to pass the TOEFL or to write essays for other classes. The other traditional student felt more advanced than the level of the class in general and was bored most of the time with the lessons.

Was there a problem with students speaking their own language in class?

This question brought out a consistent "Yes" from the traditional students, who 
all thought English only should be used in the classroom. Having other students speak their first language in class was disruptive and created barriers between students. The Otemae students felt that they had no choice but to speak Japanese to each other to help understand the lesson, or to clarify what the teacher had said or asked. One of them said that "without help in conversation we are not able to speak good English. We are afraid to ask question. Teachers are all very nice. Sometime they ask us not speak Japanese, but we speak quiet." One non-Otemae Japanese student also expressed some guilt about speaking Japanese in class and felt that it was not right, but said that many of the Chinese and Korean students also would speak their languages.

How did you feel having such a large group of Japanese women in the class?

One non-Asian traditional student felt uncomfortable in a class that was so predominantly Japanese. The student's culture was much different from the Japanese culture and felt it would have been good to learn more about Japan, but most of the Japanese students did not try to talk with other students in English. The Otemae students felt that the classes were just like class in Japan, with reading and writing lessons, and so many of their classmates all around them.

Did you interact with students outside your language or culture?

Related to the last remarks, the same traditional student had not really got to know any of the other students after eight weeks of studying together. The other students were most likely to be close friends with others who spoke the same first language. The Otemae students, as mentioned earlier, made little effort to make friends with other students outside their group. The other two traditional students said they had made many friends and were planning to continue studying at PSU in the fall term and would still see their classmates in school. 
Were you able to meet and make friends with American students?

All of the students said "No" or something related to their difficulties with pronunciation and conversational skills. It was too much effort to make friends with Americans when most people could not understand them.

What do you think could be done to improve the summer program?

This question got the most response and some specific suggestions:

"Need to give more lessons on real world things."

"Speaking and listening skills must be taught, not just easy talking."

"Very much of the lessons are too boring."

"Need to talk about American and British spelling."

"Some classes uncomfortable because they are too large."

"Languages should be mixed more. Use English only in the classroom."

"There is not enough real homework."

"There is too much homework, not enough time."

"Should be more work with pronunciation."

"Maybe have tutors during summer term is a good idea."

The most consistent remarks during the interviews were about the need for more and better training in communication skills and an insistence on trying to use English only in the classroom.

\section{DATA FROM OTEMAE COURSE EVALUATIONS}

At the end of the term, the director of the Otemae program prepared and administered a course evaluation to the Otemae students. These evaluations were in 
regard to all of their classes, not just the integrated classes in reading and writing, so the data is not completely relevant, but it is informative about their attitudes toward and evaluations of the summer program in general. In the first part, they were asked to use a scale of one (strongly disagree) to five (strongly agree) on ten questions about the summer program. Their average responses to each question are given in Table VI below.

\section{TABLE VI}

\section{OTEMAE STUDENT CLASS EVALUATIONS, PART I}

SUMMER TERM 1993

Avg. (on a scale of 1-disagree to 5-agree)

1. I have enough opportunities to speak in class.

2. I am learning a lot in this class.

3. This class is moving too fast for me; I wish the teacher would take more time

4. I am very active in this class; I participate a lot.

5. The class is too difficult for me.

6. The class is too easy for me.

7. The packet is good.

8. My instructor is willing to help me whenever I need it

9. The homework is helpful to me.

10. My instructor assigns about hours of homework every week.

It is interesting that the most negative responses came on questions five and six, which seem to contradict one another by asking if the class is too difficult on the one hand, but too easy on the other. By generally disagreeing with both statements, it seems the students are saying that things are just about right. Other than that, the only question 
that is leaning toward disagreement is question four, with a neutral response about class participation.

In the second part of the evaluation, the students were asked to give honest answers to two questions about the classes. A sampling of their answers follows each.

1. Which activities were most useful to you?

"Speaking is most useful to me."

"Discussion."

"Role play."

"Discussion is to give me opportunity to speak English."

"To speak during the class."

2. What could the instructor do to make this class better?

"Talking about questions in English."

"Assign more discussion."

"Less homework."

"I'm interested in discussion with friends."

"I just think we must not speak Japanese at all during the class."

"Please give less homework and more time."

"Less homework please."

The Otemae director also distributed a supplemental survey to all of the Otemae students regarding the entire Otemae program, including their home stays, cultural activities and food service among other items. Presented here are responses to questions from that survey regarding the language study portion of their program. 
(2.) Regarding courses: (in general)

"I wanted to take the speaking and the hearing courses."

"Class time is too short."

(8.) Please write about what you do, how you spend your time on weekends and after school during your free time:

"I went downtown to shopping."

"Go shopping."

"Read magazines and sleep."

"I went to shopping at Down Town. I visited on my friends."

"Go to movie."

"We go to shopping or conversation."

"I often go shopping with my friends or to waterfront park."

(9.) Please write your feelingslopinions about the overall program and its content, including any points you think need to be changed:

"It was very good for me, but I had to try speak with American more and more."

"I want to take speaking class."

"I want to take speaking class and listening class."

"I wanted to take speaking and listening class. I think writing and reading can study in Japan."

The traditional students completed course evaluations at the end of the summer term from only one class, and that data was not available for this study. 


\section{DATA FROM INSTRUCTOR SURVEY AND EVALUATIONS}

After the final week of class, the instructors of the reading and writing classes were given the opportunity to complete an evaluation of their classes, looking particularly at aspects of the class which affected and were affected by the integration of the two groups of students. The questions from the survey (Appendix E) are given below, with a sampling of pertinent responses from the instructors who completed the evaluation.

Did the course go as planned? If not, why not?

"Yes, although I got carried away with one project. The term was very short."

"Yes, although I scaled back what I had hoped to cover, mostly due to the students being lower skilled than I had expected."

"No, the students were much more immature than expected and had not yet learned to adapt to the American classroom style."

Were you influenced at all by the presence of the Otemae students as a homogenous group in your class (if you had any)?

"Yes, overall these students tend to participate less and are somewhat 'cliquey' when it comes to pair work."

"I tried to teach the class as though it were a regular level two reading and writing class, even though my class was $70 \%$ Otemae."

"Yes, they formed a block that was difficult to handle."

How did you handle the use of first languages among students in your class?

"I don't have a problem with the occasional use of first languages as long as 
students are negotiating meaning and are learning as a result."

"I constantly reminded them to use English, but the students spoke Japanese anyway."

"I kept reminding them and at times had to do so rather harshly."

Were you able to meet most of the needs of most of your students?

All three respondents thought they were mostly successful in addressing the needs of their students.

Do you feel the students on the whole were satisfied with class?

"On the whole, students seemed satisfied, but didn't like the out-of-class reading assignments."

"Yes, although they weren't too enthralled about reading a novel at home."

Did you enjoy teaching during the summer, and would you do it again?

"Yes! and Yes!"

"No, I didn't enjoy this summer term, but I would do it again."

"I would like to do it again to see how this group compares to others."

Were the classes too large or too small? Were the facilities and materials adequate? Did you get cooperation when needed from other faculty and staff?

All respondents thought the classes (ranging from 10 to 12 students) were the perfect size and that facilities, materials and cooperation were excellent for the most part, other than a slow copier and outdated computer equipment.

Any other comments? 
"Eight weeks is too short for one term."

"My only dislike was having a class that was $90 \%$ Japanese and $70 \%$ Otemae. A sense of camaraderie did not develop, as has happened in the past with culturally mixed classes. I know it bothered my one non-Japanese student, who felt isolated."

The departmental evaluation followed a similar line, trying to gauge the effect of the integration on classroom instruction. The survey was developed and administered by the Otemae curriculum coordinator and was responded to by three of the instructors. Again, the questions are given below with a sampling of instructor responses.

How many Otemae students is too many in one class? What percentage do you think ought to be the limit?

"More than five is too many, or $50 \%$ of the class."

"A maximum of four out of twelve would be nice."

" $50 \%$ should be the limit."

Is reading/writing appropriate for the Otemae students?

"I think they need listening/speaking more than reading/writing."

"Judging by their work, they need it."

"Their needs are so different from their desires. They are happy to learn to express their experiences in English, but seem indifferent about doing it correctly and according to English compositional style."

Did your Otemae students participatelinteract with other students?

Why? Why not?

"Not much." 
"They feel they don't communicate well enough in English."

"No, they mostly ignore the non-Otemae students in the classroom."

\section{What could be done to improve integration?}

"Fewer Otemae students per class. Place the students in listening/speaking rather than reading/writing so they will have more opportunity to communicate with other students."

“Fewer Otemae students per class. Also, they don't understand American classroom styles and teacher expectations, especially interactive exercises and problemposing [sic, i.e. problem-solving]. Perhaps some kind of introduction to ESL classroom style and teacher expectations would be good for them before they start classes."

“They don't understand our problem-posing [sic, i.e. problem-solving], interactive type of learning. If they could see it in action and discuss it early on in the term, they might interact more."

\section{ADMINISTRATOR AND COORDINATOR INTERVIEWS}

The two most striking things that came out of the interviews with the Otemae program administrator and the curriculum coordinator were 1) the political and economic factors which determined the integration of the Otemae and the traditional students into the same ESL classes during the summer term, and 2) the firm agreement that the traditional students' academic needs are being compromised because of the extra effort required on the part of the instructors to successfully integrate the Otemae students.

The political and economic situation has dictated that the Otemae students be integrated into at least some of the regular ESL classes. Part of that impetus comes from the Otemae College administration itself, which wants their students to experience actual 
academic classes at an American university, and to be able to interact with other international students and with American students. The goal is to give them an experience that is truly different from their university life at home. When there are only other Otemae students in their classes, it is little different from studying in Japan. Another element of concern is dwindling ESL enrollment, which benefitted enormously from the doubling of enrollment during the summer term with the addition of the Otemae students. This increased enrollment made it possible to retain more instructors, and to maintain the departmental budget for the summer term. These two factors alone make it imperative that a workable integration be accomplished so that the Otemae overseas program will choose PSU again in the future.

On the other hand, the realization that the Otemae population overwhelms the summer program, at least in the integrated classes, causes great concern for the academic needs of the traditional students, who are left feeling "isolated" or "bored." The curriculum coordinator suggested that in future integration efforts, it would be better to place the Otemae students in the speaking/listening classes rather than the reading/writing classes. This would enable the Otemae students to interact more, to receive more instruction in those areas where they have the greatest needs, and would allow the traditional students in the more academic reading and writing courses to stay on track.

The curriculum coordinator and the program administrator both characterized the Otemae students as being not particularly academically motivated, and had come to the U.S. mostly to learn about the U.S., to improve their English conversation, and to "go shopping." Most, if not all, of the traditional students, on the other hand, were intending to take the TOEFL exam in order to qualify for regular admission to PSU, so that they could continue their academic studies in their chosen fields. 


\section{CHAPTER VI}

\section{DISCUSSION AND CONCLUSIONS}

In this chapter the data from the instructor survey, the student survey and interviews, and the course evaluations from the instructors, the students and the administrators are discussed as a whole, with conclusions and recommendations presented based on the final analysis.

\section{SUMMARY}

Using several means to gather data, this study has presented material regarding the attitudes, motivations and expectations of the two distinct groups of students studying in the same reading and writing classes during the summer ESL session at Portland State University. It has also provided collateral and supportive information from the instructors and administrators of the program, regarding their preconceptions about the student body, their expectations for the program, and their evaluations at the end of the term.

Because the learners fell into two disparate groups, with distinct and often contrary needs, the resulting curriculum during the summer session reading and writing classes was a compromise which could not hope to adequately address the needs of both groups. These two groups of students entered the program with different motivations for studying English, and with different expectations about the summer program, which was designed to fit the more traditional students' expectations and motivations, but which suffered in that respect because of the concern for the needs and the Otemae students as 
they became apparent through the course of the term.

Using the semantic-differential survey to assess the students' attitudes, motivations, and expectations, and correlating the results with general demographic data, it was found that the students did indeed separate into two distinct groups with noticeable differences in motivation and expectations. The Otemae students also formed a large demographic block within the classes which could not be discounted in the lesson plans. Even though they had been integrated into the reading and writing classes, these skills were less important to them in the needs analysis portion of the attitude survey than were conversational and pronunciation skills. Reading and writing skills were also rated lower by the Otemae students than by the traditional students.

These and other factors lend support to the contention that the two groups of students had needs and expectations that were not wholly compatible, thereby putting a strain on the teacher/student relationships, as well as on the instructional goals. This strain was further verified in the instructor surveys, student interviews and in the departmental evaluation at the end of the summer term.

When expectations are not met, attitudes are not compatible between students and instructors, and motivations are at odds between groups of students, learning can be impaired, and the experience can be less positive for all concerned. Although the summer session, with Otemae students integrated into the regular classes, went well in the estimation of some, there is convincing evidence that there is need for improvement.

In the remainder of this chapter, the data will be assessed in light of the original research questions and hypotheses, and specific recommendations will be made for improvement of the summer integration program in future years. A successful effort will provide a better leaming environment for all concerned, and will provide incentive for overseas program directors at Otemae and other institutions to choose PSU. 


\section{QUALITATIVE ANALYSIS OF FINDINGS}

The findings were presented in the previous chapter as isolated sets of data elicited via the various specific instruments, with no explicit attempt to find relationships among them. In this section, the results of the study will be analyzed as an interrelated whole, looking at how they might support or contradict one another, specifically in light of the original research questions. Following this qualitative analysis of the findings, there is a short discussion of the unexpected results before implications are outlined and recommendations are made.

Each of the research questions is presented in turn, with relevant data from all sections of the findings brought together to provide a cohesive response.

What are the attitudes and expectations of the PSU summer session ESL instructors...

a) with regard to the students?

From the initial survey of the reading and writing instructors prior to the beginning of the summer term, it is clear that the instructors were still not quite prepared for who their students might be, nor for the students' particular set of expectations. There was still an understanding that a large group of students from Ulsan, Korea, would be attending during the summer, in addition to the traditional students and the Otemae students. If the Ulsan students had indeed attended, the demographic mix and most likely the outcome of the classes would have been different. Essentially, there was no reasonable way for the instructors to prepare for any specific mix of students, and so they were not completely prepared for the dynamics of the classes with only the Otemae students being integrated with the traditional students.

There was a consensus of opinion that the two groups of students probably would 
have different expectations and probably would have different levels of proficiency even though they had been placed in the same class levels. The one instructor who elaborated on the response to this question assumed that the Otemae students would have less academically oriented goals and expectations than would the traditional students. These opinions suggest that since the instructors in the summer program can never be sure of the student mix, they have no choice but to make some assumptions about the students' needs and expectations and to plan their curriculum primarily according to those assumptions.

\section{b) with regard to the planned curriculum?}

Because the individual instructors were working from different assumptions, their plans for the classes varied accordingly. They all expressed a willingness to remain flexible and to adapt their planned curriculum according to the needs of their students, but this actually didn't play out in some cases where the instructors expressed concern that the Otemae students in particular were not "accustomed to our interactive, (problemsolving) way of teaching and learning." These type of statements were made despite the fact that the Otemae students had already been studying in non-integrated classes for one term. So, perhaps the instructors were still willing to be flexible as far as the content of the curriculum was concerned, but not necessarily about their expectations of the students in class participation and interaction.

Concerning content, there was a wide range of response, from "fun stuff" and American cultural patterns, to reading novels, learning to write a college essay, or simply "improvement of reading and writing skills." All the instructors hoped to be able to address specific academic reading and writing skills, but two of the instructors felt the classes as a whole should not be primarily academic in focus. This variability in planned 
curriculum is understandable for the various levels, where existing language skills would determine the complexity of the subject matter being used as a tool for teaching reading and writing skills. However, where the level two class was split into three sections, and there was a divergence of opinion among the instructors about the desired academic focus of the classes, there is a concern that all the sections might not be exposed to the same material. This is especially relevant for the traditional students who would be brought back together again in level three as they progressed toward their goal of passing the TOEFL exam.

Do the demographic statistics support the identification of the two groups of students?

The instructors' assumptions that the Otemae students would form a distinct group in their classes was borne out by the demographic information elicited through the student questionnaire. As illustrated in earlier chapters, the Otemae students were primarily distinct not because of any specific traits, but rather because of the extreme coherence of the group as a whole, presenting a unified presence that essentially demanded similar treatment for all the members of the group.

The Otemae students as individuals would not have been noticeable in the ESL program, other than the short term nature of their overseas study program. Still, there are also a few individuals in the "traditional" group who are not intent on passing the TOEFL and enrolling in regular classes at PSU. The Otemae students are statistically identical within the group and the traditional students are statistically diverse. Therein lies the justification for the separation of the students into two distinct groups. Or rather, it justifies the separate status of the Otemae as a "group" with the remainder of the students being "all the rest." 
The one element that does tie "all the rest" of the students together as a group is their intent to continue study at PSU beyond the summer. That question on the survey brought an average response of 1.13 on a scale of 1 (yes) to 5 (no). Given that intent, it should be relevant in the design of a curriculum for these students to consider their long term plans and expectations, and to provide instruction accordingly. In contrast, the Otemae students are studying in the integrated ESL classes specifically during the summer term only. It seems counter-productive in the long term interests of the traditional students to cater to the temporary presence of the Otemae students. On the other hand, the Otemae students are in the U.S. for less than a year and, therefore, should not be denied the most appropriate learning experience, given their limited time.

Is there any disparity between the groups' attitudes...

a) toward learning the English language?

b) toward Americans and American culture?

More so than the traditional students, the Otemae students consistently felt that learning English was very difficult, though this is not clearly a positive or a negative attitude. Other than that, all the students started the summer term with very positive attitudes about learning English and toward Americans and American culture. There really was no difference between the two groups in this regard, only slight individual variation throughout the entire population. Again, the Otemae students as a group presented a more unified stance, reflected in the overall tighter standard deviations.

One additional aspect of attitudes that was not addressed in the study, but which could have provided even more insight into the situation, was what the students' attitudes were toward other international students from different cultures, and how they felt about interacting with them in class and outside of class. This was touched on briefly in the 
interviews, at least to gauge the amount of interaction they actually had during the course of the summer, but not what they felt about interacting.

Is there any disparity between the groups' motivations...

a) for studying English?

b) for studying at Portland State University?

This is the most striking difference between the two groups of students, as explained in the justification for delimiting the groups at all. The Otemae students are all English literature majors at Otemae College, studying at PSU for their Junior Year Abroad program. They have little integrative motivation in their home country, with few of their friends or relatives speaking English, and little opportunity to use English outside their chosen academic field. They have all been studying formal English reading and writing for eight to ten years and have come to the United States to experience living and learning in a native-speaker environment. They have come to Portland State University because of the successful cooperation between PSU, the American Heritage Association and Otemae College, based on the experience PSU was able to offer the Otemae students.

Based on the questionnaire and the interviews, the traditional students also have relatively little opportunity for using English in their home countries, but generally have a stronger motivation because of plans to study further in the United States, or because of jobs which require the use of English. It is the academic intentions of the traditional students which guides their expectations and which influences the academic focus in the ESL classes at PSU, substantiated by the responses of the instructors to the survey questions regarding the academic nature of the program. This basic difference in 
motivations between the two groups has also been verified in the interviews with the Otemae program administrator and the curriculum coordinator for the summer term, who see the Otemae students as having a very specialized agenda of "experiential learning." Is there any disparity between the groups' expectations...

a) of the program at PSU?

\section{b) for improvement in English?}

The question of expectations on the part of the students was addressed indirectly in the questionnaire by asking the students to assess their skill level in various areas, and to express their desire to learn more of those particular skills while studying at PSU. By combining their responses in Table $V$, it was possible to create a ranking of those skills which the students hoped and needed to improve the most. Because these rankings reflect the students' intrinsic motivations, these will be the skills that are favored by them in their studies and in their attention. Because disappointment is the result when reality does not live up to expectations, the fact that the Otemae students were disappointed about not being enrolled in classes focusing on conversation and pronunciation skills, those must indeed have been their expectations: to be given the instruction that they felt they needed. Even if unfulfilled needs and expectations are only perceived needs or misguided expectations, the result is still disappointment, which can adversely affect intrinsic motivation and be detrimental to long term success in second language acquisition (Green, 1993).

In general, the traditional students also favored more conversational skills, and downplayed the academic language skills, but they acknowledged the importance of both in the rankings derived from the questionnaire data in Table V. In the interviews, the traditional students also expressed various concerns about the lessons not being relevant to passing the TOEFL, or for being too much "fun and games," or for being too boring. 
This is a special concern for those academic students who are self-supporting and where every term spent in ESL classes is perceived as one more term delaying their plans to enroll in academic courses and costing more money.

Is there any disparity in expectations between the students and the instructors?

There was a definite disparity between the Otemae students' expectations for a more experiential, less academic focused curriculum and the expectations of those instructors who went ahead with a regular academic skills based "interactive, problemsolving type of class;" and conversely, between the expectations of the traditional students in an ongoing academically focused program and those instructors more inclined to focus on "fun and games," cultural activities, and a more functional approach, designed to appeal more to the Otemae students' short term goals during the summer.

What arose was a conflict between the distinct motivations and expectations of the two groups of students and the necessity for the instructors to choose one approach or the other, based on assumptions, personal teaching preferences and past experience. This conflict between the instructors' and the students' expectations is particularly borne out in the comments by the students about the teachers not understanding them, and the comments by the instructors about the students not understanding what was expected of them.

How do the students perceive the value and success of the program...

a) in terms of language learning?

From the student evaluations and the student interviews, it is clear that nearly all of the students felt good about the classes and the progress they had made as individuals. All of them thought the instructors were nice and did a good job of teaching, although it was common for the students to express concern when teachers were not able to answer 
grammatical questions clearly and with authority. The major disappointment, as explained earlier, was on the part of the Otemae students concerning their lack of progress with conversational skills.

b) in terms of social integration?

Related to the lack of progress in conversational skills, the Otemae students also felt that they were unable to make friends with other, non-Japanese, students because of their limited ability with spoken English. This put them in the undesirable position of always being part of their own group for social interaction. From the interviews with the program director and coordinator, it was revealed that one of the major complaints of the Otemae students was their constant association only with their own group while at school. In the interviews also, they emphasized that they came to the U.S. on the overseas program to meet Americans and interact in American culture to learn more about it. However, from some instructors' points of view, it would seem the Otemae students were the ones ignoring the other students in class, and who were unwilling to participate and interact. This is probably due to the nature of Japanese culture, and the place in that culture of young unmarried women, which the Otemae program administrators said discouraged them from taking risks and speaking out as individuals.

As for the traditional students, their only concern was the apparent lack of interest on the part of the Otemae students to interact, especially in those classes where the Otemae made up a large majority of the students, leaving the few traditional students feeling "isolated."

How is the appropriateness of the program evaluated by the instructors and administrators?

Two of the instructors and the curriculum coordinator were convinced that the Otemae students should in the future be integrated into the listening and speaking ESL 
classes rather than the reading and writing classes, based on their intuitive understanding of the situation and their direct experience in the classrooms. The integration of the students in the reading and writing classes was not seen as a failure or as completely inappropriate, but was definitely seen as causing unanticipated feelings of frustration on the part of the Otemae students and their instructors. These feelings are supported by the students responses to the initial questionnaire where they rated academic reading and writing skills quite low on the scale, and in their evaluations of the program where they nearly unanimously wished they could have been in the listening and speaking classes.

Two reasons for the integration of the Otemae students into the reading and writing classes instead of the listening and speaking classes in the first place included scheduling limitations, and a desire on the part of the administration to give the students a more academic experience.

\section{UNANTICIPATED RESULTS}

There were several surprising findings that were not anticipated, primarily revealed in the surveys returned by the instructors, both at the beginning of the term and at the end of the term. Principally, it was surprising that not only was there not a formal curriculum being followed, but that the individual instructors had different ideas amongst themselves about how the classes should be conducted and what type of focus the program should have. Of course, this flexibility and variation provided for more opportunity to shape the courses to the needs of the particular students that ended up filling the classes, but in reality just resulted in a more complex interplay of expectations between the students and the instructors.

Even though'all of the instructors initially expressed their openness to flexibility 
and their intention of conducting some sort of in-class needs analysis, for the most part they stayed with the general focus they had individually had in mind from the start, and were either frustrated by or felt sympathy for those students who weren't fitting in. The lack of a common curriculum for the program as a whole could be a potential problem in the future, if the results of this study are any indication.

Another unexpected finding was the discrepancy between the students' feelings that the classes were too large, and the instructors' that they were "just right." It would be interesting to know on what basis the instructors are judging the appropriateness of the class size if not on the impressions of the students. 'The class' is the students, so if they think the class is too large for them to feel comfortable or to get adequate attention from the instructor, then it is too large, regardless of the instructor's opinion. After all, even though a successful educational process is a partnership between students and instructors, the program is predicated primarily on the students' desire and ability to learn, not on the instructors' desire and ability to teach. The program would not exist without the students, but given students, the right instructors can be hired. Perhaps the instructors' opinions on class size were tempered by knowledge of budget constraints, and they realized that the class size was the best that could be accomplished under the circumstances. Also, perhaps the students were feeling not so much that there were simply too many students in the classes, but that there were too many Otemae students in the classes.

One last finding that was unanticipated was the degree of influence that the Otemae College administration had on the initial decision to integrate the Otemae students into the regular ESL program. With this realization comes the necessity of considering further input from Otemae College if any changes are to be made in future summer sessions. 


\section{IMPLICATIONS OF THE STUDY}

The final research question that was posed in the introduction to the study asked:

\section{What recommendations could be made to make the program more appropriate?}

Based on the findings presented in the study and the analysis of the data in this

chapter, several immediate recommendations for improvement become apparent. These include integrating the Otemae students into speaking and listening classes instead of reading and writing classes, having a curriculum designed with both groups in mind that instructors would have available before the summer term begins, conducting a term by term needs analysis, providing introductory sessions on American classroom style, and attempting to reduce the percentage of Otemae students in any given class by actively recruiting more international ESL students to PSU.

The first of these recommendations, integrating the Otemae students into the speaking and listening classes instead of the reading and writing classes, would address many of the concerns expressed in the study by the students, the instructors and the administrators. First, the students would be getting the instruction that they feel is most important to them during their short experience in the United States. For many of them, this will probably be their only experience in an English-speaking environment, and they should be given every chance to take advantage of the opportunities that this provides. As many of the Otemae students mentioned, they can study reading and writing skills in Japan. What they can't get in Japan is conversational skills, pronunciation practice with native speakers, and interaction with Americans in their own cultural setting.

Second, having these students in speaking and listening classes would also provide them with the opportunity to interact more as a natural part of the lessons, with appropriate attention and feedback in the areas where they need the most help. Keeping 
them out of the reading and writing classes would enable those instructors to maintain the appropriate focus for the traditional academic students. In listening and speaking classes, everyone would have basically the same incentives and the same needs, regardless of which group they fell into demographically.

Third, because of the more general focus in the speaking and listening classes, it would be possible to have a consistent, program-wide curriculum prepared for new instructors that should be appropriate for any mix of students who were placed in the same classes based on proficiency testing. This leads directly to the second recommendation - for just such a program-consistent curriculum.

With a program-wide curriculum, incoming teachers, hired specifically for the summer term, would know what they are expected to cover, and the students would be receiving similar instruction regardless of which section they chanced into for their particular level. This kind of a curriculum could be developed by the actual instructors who have taught in the program and who would know what has worked and what hasn't. Actually collecting the information and putting together a formal reference document would be a great help not only to new instructors, but to the administrators who are evaluating the program and to the organizers of the various overseas study programs like Otemae's who must justify their decisions to send students to PSU. Of course, as Nunan (1988) points out, a set curriculum cannot hope to cater to a diverse group of students, and this is the reason for suggesting that the integrated classes be speaking and listening, where the diversity of the students will be less relevant because of their likely more common needs and goals, as expressed by all of the students in the study.

The third and fourth recommendations are closely related and are designed to alleviate the type of frustrations and conflicts that arose during the summer term that was 
studied here. On the one hand, a formal needs analysis should be conducted at the beginning of the term to determine the attitudes, motivations and expectations of the students who actually enroll in the classes, and to assist in the fine tuning of the curriculum for the particular population that is present. Hand in hand with this information from the students should be a short introductory session at the beginning of the term giving to the students the information they will need to know about how the class will be managed and what will be expected of them, as suggested by two of the instructors who made comments on the evaluation survey.

The final recommendation is the recruitment of more international students to PSU's ESL program. If this is not actively eing pursued, it should be, based on the instructors' and administrators' concerns about declining enrollments and the overwhelming influence that a cohesive group like the Otemae students can have on a small initial population. If the enrollment figures had been double or triple what they were during the summer session of 1993, the effect of the Otemae students would have been much less apparent, but of course,would also not have drawn attention to some of the other problems that only became apparent during the course of this study.

All of these recommendations are designed to eliminate the kind of conflicts that arise when students and instructors have different expectations, and when groups of students in the same classroom have different motivations and expectations. When students suffer disappointments, or are frustrated with what is being taught or how it is being taught, their interest declines and their intrinsic motivation suffers as a result.

Green (1993) points out that contrary to the popular assumption that students either enter the language classroom with or without motivation to learn, and it is simply the teacher's lot to accept what the students bring into the class, he counters that 
"Learner motivation is in a constant state of flux brought about by a concatenation of developmental, personality and attitudinal factors (p. 2)." It is those attitudinal factors which can be influenced by the instructor and by the curriculum and by fellow students. If students have reasons for a positive attitude, and their expectations are fulfilled in a reasonable way, their intrinsic motivation will be sustained and there is a much greater chance of long term success in second language acquisition.

\section{LIMITS OF THE STUDY}

Because this is an intact group being studied, there has been no attempt to generalize beyond this particular setting. The study is primarily qualitative in nature, though it relies on the statistical data provided by the semantic differential attitude survey given to the students to determine their attitudes, expectations, and motivations. The data derived from this survey lacks rigorous quantitative significance beyond the confines of this study because of the small sample size, the lack of control groups, and the plethora of confounding factors which cannot be anticipated, isolated, or controlled. It is used only as a tool to illustrate the qualitative analysis being made.

Also, although the intent of this research is to provide direct insight into the effectiveness of the summer session ESL program at PSU, as it is affected by and affects in return the attitudes, motivation, and expectations of the two groups enrolled in the program, the results cannot wholly be extrapolated to future summer sessions, since the demographic makeup of the group being studied is probably unique. It should, however, provide guidance for administrators and coordinators, demographic information for future instructors, and valuable qualitative feedback which may not be generalizable, but which adds to the body of data available for more rigorous quantitative studies. 
Effectiveness itself is a term that is usually associated with some definable goal that can be empirically measured and objectively compared to the results of a controlled study. In this study, however, effectiveness refers to the more qualitative goals that have been established by program coordinators, individual instructors, and students themselves. These general goals and expectations are then compared to the actual experience of all the participants in the program.

Because the direct, subjective attitudes and impressions of the individuals involved are so crucial to long term success in education, these factors have been given particular consideration in this study, as opposed to quantitative measures of proficiency and improvements in proficiency as a function of attitudes or motivations. It has been argued here that successful language learning in the long run is seriously affected by attitudes, motivations, and expectations, and those individuals who achieve empirically measurable increases in proficiency despite negative attitudes, lack of motivation, and unmet expectations are the exception and need not be considered in the contention that proficiency measures are superfluous in any measure of a language teaching program's "effectiveness." It is the contention in this study that positive attitudes, sustained motivation, and fulfilled, realistic expectations are the key to long term success in second language acquisition.

\section{RECOMMENDATIONS FOR FURTHER RESEARCH}

If the recommendations in the previous section were implemented in future years, it would be informative to conduct another study similar to this one to judge whether the suggested changes had merit, or whether the same type of problems and conflicts were still apparent, simply because of the presence of the two different groups of students in 
the same classes. Additionally, proficiency scores could be analyzed for the same group of students to provide a more quantitative analysis of the effects of the integration during the summer session. This type of analysis would also be appropriate in a longitudinal study of the progress of traditional students who happened to be a part of the integrated classes during the summer.

Another area of research which could shed light on the set of expectations that the students bring with them into the classroom could be to look at the effect of common cultural values and educational experience within a homogenous group like the Otemae students. These common values and experiences most likely play a very large role in the attitudes the students have toward learning English in the U.S. and toward working and studying with other students from a wide variety of cultural and linguistic backgrounds. The very homogeneity of the Otemae group is likely the strongest influence in the development of their attitudes and motivations. The results of this study suggest that rich insights could be gained by further study in this direction. 


\section{REFERENCES}

Alpetkin, C. (1981). Sociopsychological and pedagogic considerations in L2 acquisition. TESOL Quarterly, 15, 275-284.

Au, S. Y. (1988). A critical appraisal of Gardner's social-psychological theory of second language (L2) learning. Language Learning, 38, 75-100.

Ausubel, D. P. (1968). Educational psychology: A cognitive view. New York: Holt, Rinehart and Winston.

Bacon, S. M., \& Finnemann, M. D. (1990). A study of the attitudes, motives, and strategies of university foreign language students and their disposition to authentic oral and written input. The Modern Language Journal, 74, 459-473.

Boyle, J. P. (1987). Intelligence, reasoning, and language proficiency. The Modern Language Journal, 71, 277-284.

Brown, H. D. (1987). Principles of language learning and teaching.Englewood Cliffs, New Jersey: Prentice Hall Regents.

Brown, J. D. (1988). Understanding research in second language learning. Cambridge: Cambridge University Press.

Carroll, J. B. (1990). Cognitive abilities in foreign language aptitude: Then and now. In T. S. Parry \& C. W. Stansfield (Eds.), Language aptitude reconsidered (pp. 1129). Englewood Cliffs, New Jersey: Prentice Hall Regents.

Chihara, T., \& Oller, J. W. (1978). Attitudes and attained proficiency in EFL: A sociolinguistic study of adult Japanese speakers. Language Learning, 28, 55-68.

Child, D. (1984). Motivation and the dynamic calculus-a teacher's view. Multivariate Behavioral Research, 19, 288-298.

Clément, R., \& Kruidenier, B. G. (1983). Orientations in second language acquisition: I. The effects of ethnicity, milieu, and target language on their emergence. Language Learning, 33, 273-291. 
Corder, S. P. (1973). Introducing applied linguistics. Harmondsworth: Penguin.

Currall, S. C., \& Kirk, R. E. (1986). Predicting success in intensive foreign language courses. The Modern Language Journal, 70, 107 113.

Day, J. T. (1987). Student motivation, academic validity, and the summer language program abroad: An editorial. The Modern Language Journal, 71, 261-266.

Ehrman, M. (1990). The role of personality type in adult language learning: An ongoing investigation. In T. S. Parry \& C. W. Stansfield (Eds.), Language aptitude reconsidered (pp. 126-178). Englewood Cliffs, New Jersey: Prentice Hall Regents.

Ehrman, M., \& Oxford, R. (1989). Effects of sex differences, career choice, and psychological type on adult language learning strategies. The Modern Language Journal, 73, 1-13.

Ély, C. M. (1986). An analysis of discomfort, risk taking, sociability, and motivation in the L2 classroom. Language Learning, 36, 1-25.

Ely, C. M. (1988). Personality: Its impact on attitudes toward classroom activities. Foreign Language Annals, 21, 25-32.

Ely, C. M. (1989). Tolerance of ambiguity and use of second language strategies. Foreign Language Annals, 22, 437-445.

England, L. (1982). The role of integrative motivation in English as a second language learning among a group of foreign students in the United States. Paper presented at the 16th Annual Convention of Teachers of English to Speakers of Other Languages (TESOL), Honolulu, HI. (ERIC Document Reproduction Service No. ED 222 044).

Fayer, J. M., \& Krasinski, E. (1984). Measuring student attitudes for curriculum planning: A study of ESL students at the University of Puerto Rico. Paper presented at the 18th Annual Convention of Teachers of English to Speakers of Other Languages (TESOL), Houston, TX. (ERIC Document Reproduction Service No. ED 245 551).

Gardner, R. C. (1980). On the validity of affective variables in second language acquisition: Conceptual, contextual, and statistical considerations. Language Learning, 30, 255-270. 
Gardner, R. C. (1988). The socio-educational model of second-language learning: Assumptions, findings, and issues. Language Learning, 38, 101-126.

Gardner, R. C. (1990). Attitudes, motivation, and personality as predictors of success in foreign language learning. In T. S. Parry \& C. W. Stansfield (Eds.), Language aptitude reconsidered (pp. 179-221). Englewood Cliffs, New Jersey: Prentice Hall Regents.

Gardner, R. C., \& Gliksman, L. (1982). On “Gardner on affect”: A discussion of validity as it relates to the attitude/motivation test battery: A response from Gardner. Language Learning, 32, 191-200.

Gardner, R. C., Lalonde, R. N., \& Moorcroft, R. (1985). The role of attitudes and motivation in second language learning: Correlational and experimental considerations. Language Learning, 35, 207-227.

Gardner, R. C., \& Lambert, W. E. (1972). Attitudes and motivation in second-language learning. Rowley, Massachusetts: Newbury House.

Gelder, S. M. (1992). A study of the attitudes and opinions of students and teachers in the English for Non-Native Residents program at Portland State University. Unpublished masters thesis, Portland State University.

Genesee, F., \& Hamayan, E. (1980). Individual differences in second language learning. Applied Psycholinguistics, 1, 95-110.

Genesee, F., Rogers, P, \& Holobow, N. (1983). The social psychology of second language learning: Another point of view. Language Learning, 33, 209-224.

Gradman, H. L., \& Hanania, E. (1991). Language learning background factors and ESL proficiency. The Modern Language Journal, 75, 39-51.

Graham, J. G. (1987). English language proficiency and the prediction of academic success. TESOL Quarterly, 21, 505-521.

Green, C. F. (1993). Learner drives in second-language acquisition. English Teaching Forum, 9, 3-11.

Harshbarger, L. (1990). The attitude-proficiency relationship: A non-linear perspective. Paper presented at the 9th World Congress of Applied Linguistics, Thessaloniki, Greece. (ERIC Document Reproduction Service No. ED 332 503). 
Hartill, L. (1984). Attitude, motivation, and the proficiency scores of college-level international students. Unpublished research paper, Portland State University.

Horwitz, E. K. (1985). Using student beliefs about language learning and teaching in the foreign language methods course. Foreign Language Annals, 18, 333-340.

Krashen, S. (1981). Second language acquisition and second language learning. Oxford: Pergamon Press.

Krashen, S. (1982). Principles and practice in second language acquisition. Oxford: Pergamon Press.

Larsen-Freeman, D., \& Long, M. H. (1991). An introduction to second language acquisition research. New York: Longman.

Lombardo, L. (1988). Language learners' needs, interests and motivation: A survey of EFL students in an Italian economics faculty. Rome: Centro Informazione Stampa Universitaria. (ERIC Document Reproduction Service No. ED 304 006).

Lukmani, Y. M. (1972). Motivation to learn and language proficiency. Language Learning, 22, 261-273.

Maslow, A. H. (1954). Motivation and personality. New York: Harper \& Brothers.

Nelson, F. H., Lomax, R. G., \& Perlman, R. (1984). A structural equation model of second language acquisition for adult learners. Journal of Experimental Education, 53, 29-39.

Neufeld, G. G. (1979). Towards a theory of language learning ability. Language Learning, 29, 227-241.

Nida, E. A. (1957). Motivation in second language learning. Language Learning, 7, (3) 11-16.

Nunan, D. (1988). The learner-centred curriculum. Cambridge: Cambridge University Press.

Oller, J. W. (1982). Gardner on affect: A reply to Gardner. Language Learning, 32, 183-189. 
Oller, J. W., Hudson, A. J., \& Liu, P. F. (1977). Attitudes and attained proficiency in ESL: A sociolinguistic study of native speakers of Chinese in the United States. Language Learning, 27, 1-23.

Oxford, R. L. (1990). Styles, strategies, and aptitude: connections for language learning. In T. S. Parry \& C. W. Stansfield (Eds.), Language aptitude reconsidered (pp. 67-125). Englewood Cliffs, New Jersey: Prentice Hall.

Parry, T. S., \& Child, J. R. (1990). Preliminary investigation of the relationship between VORD, MLAT, and language proficiency. In T. S. Parry \& C. W. Stansfield (Eds.), Language aptitude reconsidered (pp. 30-66). Englewood Cliffs, New Jersey: Prentice Hall Regents.

Parry, T. S., \& Stansfield, C. W. (Eds.). (1990). Language aptitude reconsidered. Englewood Cliffs: Prentice Hall Regents.

Rodriguez-Brown, F. V., \& Ruesta, M. B. (1987). Attitudes and motivational factors in second language learning. Unpublished research paper, University of Illinois at Chicago. (ERIC Document Reproduction Service No. ED 288 354).

Rubin, J. (1975). What the "good language learner" can teach us. TESOL Quarterly, 9, 41-51.

Schumann, J. H. (1975). Affective factors and the problem of age in second language acquisition. Language Learning, 25, 209-235.

Skehan, P. (1989). Individual differences in second-language learning. London: Edward Arnold.

Spaulding, C. L. (1992). Motivation in the classroom. New York: McGraw-Hill.

Spolsky, B. (1969). Attitudinal aspects of second language learning. Language Learning, 19, 271-283.

Strong, M. (1984). Integrative motivation: Cause or result of successful second language acquisition? Language Learning, 34, 1-14.

Svanes, B. (1987). Motivation and cultural distance in second-language acquisition. Language Learning, 37, 341-359. 
Van Patten, B., Dvorak, T. R., \& Lee, J. F. (1987). Foreign language learning: A research perspective. Cambridge: Newbury House.

Wangsotorn, A. (1987). Relationship between learning modes and the beginners' success in English. RELC Journal, 18, 31-45. 
APPENDIX A

PRELIMINARY INSTRUCTOR SURVEY 
Teacher Expectations for the Summer ESL Session at PSU

1. Name:

2. Class you will be teaching:
Level
Skill Areas
Hrs/Wk.

3. How many students do you expect to be in the class?

4. What language backgrounds do you expect the students to come from?

5. Do you think your students will all be at a similar level of proficiency?

6. Do you think all your students will have similar expectations from the class?

7. What do you think their expectations and motivations might be?

8. Do you plan to do any needs assessment at the beginning of the term? Such as?

9. Do you plan to provide individualized instruction based on needs? Or other criteria, such as first language?

10. Is your curriculum for the class pretty much decided beforehand? If so, by whom? And, if so, is it based on a specific text? 
11. What broad topics, skills, strategies, or functions do you hope to cover?

12. Do you feel this program is primarily focused on academic language skills?

13. How will you know if your instruction has been successful? How will the students know?

14. Would you be willing to allow your students to fill out a short questionnaire on the first day of class? 
APPENDIX B

STUDENT SURVEY QUESTIONNAIRE 


\section{PSU SUMMER SESSION ESL STUDENT SURVEY OF ATTTTUDES, MOTIVATIONS AND EXPECTATIONS}

\section{To participating ESL instructors:}

Thank you so much for assisting me with my thesis project. With your help, I should be able to gather the data I need to make a worthwhile study of the summer program. The survey is to be completed by the students who wish to do so. They are not required to complete it, but to satisfy the need for confidentiality, all students are asked to take a survey home with them and to bring it back tomorrow (Thursday, July 22) either filled in or not and place it with the rest of the forms in an envelope. I have created an introductory script for you to read to the students after the forms have been distributed. If you feel this is inadequate in any way, please feel free to ad-lib so that the intended meaning is conveyed.

\section{INTRODUCE THE ACTIVITY}

"A student teacher wants to know some things about your English studies, and is asking each of you to answer the questions on this form, but ONLY if you want to. Please take the form home and THEN decide if you want to answer the questions or not. Bring it back to this class tomorrow either way, and I will collect them for him."

\section{DISTRIBUTE ONE FORM TO EACH STUDENT IN THE CLASS.}

- Don't worry about students who are absent.

- Tally the number of forms distributed so that the same number can be collected.

- Read the introduction from the first page of the survey: 
"This survey is part of a research project. You are not required to complete the survey, but your answers may help improve the program for future students. Choosing not to complete the survey will not affect your grades - this is not part of your ESL class. If you do choose to complete the survey your name will not be used and your identity will be kept confidential."

"If you decide to answer the questions, please remember to fill out the personal information on the first page."

\section{ANSWERING QUESTIONS}

"Look at the questions for the next few minutes and read the examples on page 2 and 3. If there are any words that you don't understand, I can give you a synonym to help you out, but I would like you to answer the questions on your own this evening. If any question is too difficult, just skip it."

- If students are unclear about how to complete the form, refer to the examples first, and then, if there are still problems, make up an example and put it on the overhead or the blackboard for clarification. Try not to use further actual examples from the survey.

Thanks again for your help. I hope this goes smoothly and takes a minimum of your time. I will be back tomorrow at this same time to collect the completed surveys. 


\section{To Participating ESL Students:}

This survey is part of a research project. You are not required to complete the survey, but your answers may help improve the program for future students. Choosing not to complete the survey will not affect your grades - this is not part of your ESL class. If you do choose to complete the survey your name will not be used and your identity will be kept confidential. Thank you for your help.

Confidential Personal Information

1) Name

2) Birth Date:

3) Sex: F M

4) Nationality:

5) Language:

6) Language of mother: father:

7) Does your father speak English (Yes/No)?

8) Does your mother speak English (Yes/No)?

9) What languages do you speak?

10) Years of university education:

11) What is your major subject? (History, Business, English, etc.):

12) How many years have you studied English?

13) ESL level at Portland State:

14) How long have you been in the United States? 
Survey Directions: Mark the space that you most agree with.

Look at this sample for help:

If I knew just a little about American culture, I would mark an "X" in the space I felt showed how much I knew about American culture.

SAMPLE: I know (a lot X very little) about American culture.

15) I think learning English is (easy very difficult).

16) I think learning English is (boring fun).

17) I (really like don't like) the sound of English.

18) I (don't want want) to make American friends.

19) I (really like don't like) most Americans.

20) I know (a lot very little) about American culture.

21) I (don't want want) to study in the U.S. after the summer.

22) I will (often never) speak English in my country.

23) I will (never often) need to use English for my job.

24) English is (my choice required) for college.

25) My parents (want don't want) me to study English.

26) Learning about the U.S. is (not important very important).

27) Most of my friends (speak do not speak) English.

28) Speaking English is (not important very important). 
For each of the following......What is your skill level?.....and...Do you want to learn more?

For example: If I am not good at pronunciation, but I very much want to learn better pronunciation, I would mark the spaces like this:

(not good............very good ) (not much............very much)

.....) pronunciation

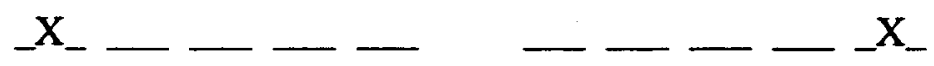

What is your skill level? Do you want to learn more? (not good.............very good ) (not much............very much)

29) taking notes

30) reading literature and poetry

31) pronunciation

32) grammar

33) reading textbooks

34) conversation

35) history of the language

36) writing for class

37) business writing

38) American culture

39) understanding Americans

40) reading newspapers

41) vocabulary

42) speaking to the class

43) listening to radio \& TV

44) spelling

45) typing 


\section{APPENDIX C}

\section{FOLLOW-UP STUDENT INTERVIEW FORMAT}


Basic guiding questions should cover the following points:

1. How did you like your ESL classes this summer?

2. What classes did you enjoy the most? The least?

3. Did you learn as much as you hoped to at the start of the summer?

4. Were there any specific problems that you had in class?

5. Do you feel your needs as a student were understood?

6. Was there a problem with students speaking their own language in class?

7. How did you feel having such a large group of Japanese women in the class?

8. Did you interact with students outside your language or culture?

9. Were you able to meet and make friends with American students?

10. What do you think could be done to improve the summer program? 
APPENDIX D

OTEMAE COURSE EVALUATION 


\section{OTEMAE COURSE EVALUATION}

Summer 1993

Please give an honest answer to the following questions. Your opinions will provide valuable information for our evaluation of the success and direction of the classes.

\section{Part I}

Please circle the number which corresponds to your opinion of each question. Use the following scale to answer each question.

$1=$ strongly disagree $\quad 2=$ disagree $\quad 3=$ agree somewhat $\quad 4=$ agree $\quad 5=$ strongly agree

1. I have enough opportunities to speak in class.

2. I am learning a lot in this class.

3. This class is moving too fast for me; I wish the teacher would take more time.

4. I am very active in this class; I participate a lot.

5. The class is too difficult for me.

6. The class is too easy for me.

7. The packet is good.

8. My instructor is willing to help me whenever I need it.

9. The homework is helpful to me.

10. My instructor assigns about ....... hours of homework every week.

\section{Part II}

Please give an honest answer to the following questions:

1. Which activities were most useful to you?

2. What could the instructor do to make this class better? 


\section{APPENDIX E}

\section{FOLLOW-UP INSTRUCTOR SURVEY}


COURSE EVALUATIONS

Now that the term is completed and I have gathered all of my data from the students, I would like to have some final comments from you about the way the classes went. I would be very grateful if you could take a few minutes to answer the following questions briefly and return the completed form early next week. Thanks for your time and cooperation.

1. Did the course go as planned? If not, why not?

2. Were you influenced at all by the presence of the Otemae students as a homogenous group in your class (if you had any)?

3. How did you handle the use of first languages among students in your class?

4. Were you able to meet most of the needs of most of your students?

5. Do you feel the students on the whole were satisfied with class?

6. Did you enjoy teaching during the summer, and would you do it again?

7. Were the classes too large or too small? Were the facilities and materials adequate? Did you get cooperation when needed from other faculty and staff?

8. Any other comments? 


\section{APPENDIX F}

\section{DEPARTMENTAL EVALUATION SURVEY}


TO: Reading/Writing Instructors:

FROM: Otemae ESL Curriculum Coordinator

REGARDING: Integration of Otemae Students

I am interested in getting your thoughts on the relative success or failure of the attempt to integrate the Otemae students into the regular morning ESL classes. I suspect the experience of individual instructors will vary according to the percentage of Otemae students in their class, to other factors. I am hoping that we can learn from you, and consider some of your suggestions and comments in our decisions for next year.

How many Otemae students is too many in one class? What percentage do you think ought to be the limit?

Is reading/writing appropriate for the Otemae students?

Did your Otemae students participate/interact with other students?

Why? Why not?

What could be done to improve integration? 